\title{
BORN WITH A SILVER SPOON? DANISH EVIDENCE ON WEALTH INEQUALITY IN CHILDHOOD
}

\author{
Simon Halphen Boserup
}

Wojciech Kopczuk

Claus Thustrup Kreiner

Working Paper 22549

http://www.nber.org/papers/w22549

\section{NATIONAL BUREAU OF ECONOMIC RESEARCH \\ 1050 Massachusetts Avenue \\ Cambridge, MA 02138}

August 2016

Financial support from the Economic Policy Research Network (EPRN) and the Danish Council for Independent Research (DFF - 1329-00046) is gratefully acknowledged. The views expressed herein are those of the authors and do not necessarily reflect the views of the National Bureau of Economic Research.

NBER working papers are circulated for discussion and comment purposes. They have not been peer-reviewed or been subject to the review by the NBER Board of Directors that accompanies official NBER publications.

(C) 2016 by Simon Halphen Boserup, Wojciech Kopczuk, and Claus Thustrup Kreiner. All rights reserved. Short sections of text, not to exceed two paragraphs, may be quoted without explicit permission provided that full credit, including ()$^{\text {notice, }}$ is given to the source. 
Born with a Silver Spoon? Danish Evidence on Wealth Inequality in Childhood

Simon Halphen Boserup, Wojciech Kopczuk, and Claus Thustrup Kreiner

NBER Working Paper No. 22549

August 2016

JEL No. D31,J62

\begin{abstract}
We study wealth inequality in childhood using Danish wealth records from three decades. While teenagers have some earnings, we estimate that transfers account for at least 50 percent of wealth at age 18, and much more so for the rich children. Inheritance from grandparents does not appear quantitatively important, but we do find evidence that children receive inter vivos transfers. While wealth holdings are small in childhood, they have strong predictive power for future wealth in adulthood. Asset holdings at age 18 are more informative than parental wealth in predicting wealth of children many years later when they are in their 40s. Hence, childhood wealth reveals significant heterogeneity in the intergenerational transmission of wealth, which is not simply captured by parental wealth alone. We investigate why this is the case and rule out that childhood wealth in itself can accumulate enough to explain later wealth inequality. Our evidence indicates that childhood wealth is a proxy for a broad set of circumstances related to intergenerational transmission and future wealth accumulation, including savings/investment behavior and additional transfers.

Simon Halphen Boserup

Department of Economics

University of Copenhagen

Øster Farimagsgade 5

Building 26

DK-1353 Copenhagen K

Denmark

shb@econ.ku.dk

Wojciech Kopczuk

Columbia University

420 West 118th Street, Rm. 1022 IAB

MC 3323

New York, NY 10027

and NBER

wk2110@columbia.edu

Claus Thustrup Kreiner

Department of Economics

University of Copenhagen

Øster Farimagsgade 5

Building 26

DK-1353 Copenhagen K

Denmark

claus.thustrup.kreiner@econ.ku.dk
\end{abstract}




\section{Introduction}

Does inequality in consumption possibilities across individuals start early in life? Some people possess economic resources already in early childhood. ${ }^{1}$ Having significant wealth in early childhood is a marker for coming from a family that makes direct transfers to their offspring, making these children "born with a silver spoon." 2

In this paper, we use Danish wealth records to study wealth inequality observed already in childhood. Our analysis is based on wealth records covering all child-parents pairs of more than fifty child cohorts born since 1960 and with wealth information for a nearly thirty year period from 1983 to 2011. Beyond characterizing childhood wealth inequality and its sources, a key finding is that childhood wealth, despite being small, is very informative about wealth in adulthood, also after controlling for wealth of parents. While we cannot fully disentangle why this is so, we provide evidence suggesting that childhood wealth is related to future transfers from parents and intergenerational transmission of savings/investment behavior, pointing to important heterogeneity in intergenerational wealth transmission not accounted for by parental wealth alone.

Our study is related to the recent literature on the evolution of wealth inequality and wealth formation across generations (see e.g. the symposium in the winter 2015 volume of the Journal of Economic Perspectives). Until recently intergenerational mobility in wealth was much less studied than other outcomes such as income, education, and health (see surveys by Solon 1999 and Black and Devereux 2011) although it in many ways is at least as interesting. For example, intergenerational transmission of wealth at the top of the distribution underlies concerns of Piketty (2014) about self-perpetuating wealth inequality. Our own study (Boserup, Kopczuk, and Kreiner 2015) for Denmark on wealth holdings of adults across multiple generations shows that Denmark has higher wealth mobility than the US, in line with recent evidence showing higher income mobility in Denmark than in the US (Chetty, Hendren, Kline, and Saez 2014). ${ }^{3}$

\footnotetext{
${ }^{1}$ While inequality in wealth reflects differences across individuals in consumption possibilities, there exist earlier life outcomes such as birth weight that predict differences in future consumption possibilities (Black et al. 2007), but without in itself entering the budget constraint of the individual.

${ }^{2}$ The old phrase "born with a silver spoon" has been used for centuries about individuals who were born into a wealthy family. It appears in English writing in the early 18th century in a translation of the novel Don Quixote (Motteux 1719).

${ }^{3}$ Charles and Hurst (2003) provide estimates of intergenerational wealth mobility for the US using the PSID survey data. They review a few older studies of intergenerational wealth mobility. Recent studies on intergenerational wealth mobility include Boserup, Kopczuk, and Kreiner (2016) and Elinder, Erixson, and Waldenström (2016) who study the role of bequests for wealth inequality of the next generation. Black, Devereux, Lundborg, and Majlesi (2015) and Fagereng, Mogstad, and Rønning (2015) use data for adoptees to study the role of nature versus nature in explaining the intergenerational correlation in wealth. Clark and Cummins (2014) and Adermon, Lindahl, and Waldenström (2015) contribute to the growing literature on multigenerational mobility (Solon 2015) by estimating wealth mobility
} 
Our study is also related to a large literature on intergenerational wealth transfers (see surveys by Laitner 1997, Laferrère and Wolff 2006, Arrondel and Masson 2006, and Kopczuk 2013) that is focused on understanding motivations behind them, as well as their consequences for the level and mode of giving (inheritance vs inter vivos) and behavior of donors and recipients (wealth accumulation, consumption, labor supply, entrepreneurship, tax-related responses).

We provide four sets of results. Firstly, we provide descriptive evidence on the size and inequality of wealth in childhood. Our results show that only few children own any assets until age 12 - going from 1 percent for one year old children to 10 percent at age 12 - and that the level of wealth is modest even among the wealthiest in early childhood. For example, the level of wealth equals $1 / 5$ of GDP per capita for the top 1\% wealthiest among one year old children. By late teens and when moving into adulthood, most children have at least a bank account, and some have equities, but their overall level of wealth is still small. On the other hand, the average wealth levels of the top $1 \%$ (top $0.1 \%$ ) wealthiest are non-trivial as they have climbed up to five (twenty) times GDP per capita at age 18.

Secondly, we study the underlying sources of childhood wealth. This is not directly observable from the data, but until the age of 12 we can deduce that wealth stems entirely from transfer payments as it is illegal to work before the age of thirteen. Using evidence from payroll records and capitalizing the flow of earnings before adulthood leaves about 50 percent of wealth at age 18 unexplained. This residual equals the capitalized value of wealth transfers minus child spending, implying that transfers explain at least 50 percent of wealth. For the top $1 \%$ (top $0.1 \%$ ) wealthiest, at least 92 percent (99 percent) of wealth at age 18 has to come from transfers.

By comparing wealth of children with living grandparents with other children, both in the crosssection and in an event study, we can show that inheritance from grandparents is not quantitatively important. This leaves inter vivos transfers as the main explanation. While we cannot observe inter vivos transfers directly, we provide evidence that changes in wealth of children exhibit bunching at kinks in the tax schedule for gifts. This confirms that at least some of the wealth of children is due to tax-motivated inter vivos transfers, in line with evidence showing that tax incentives matter for inter vivos transfers in adulthood (e.g., Bernheim, Lemke, and Scholz 2004, Joulfaian 2005, and Kopczuk 2007).

Thirdly, we provide nonparametric evidence of the relationship between childhood wealth and wealth of parents. A positive relationship exists already when children are one year old. For parents across multiple generations for the UK and Sweden, respectively. 
with wealth below percentile 80, only around 0.5-1 percent of one year old children own any assets, while as many as 7 percent of the children own assets when parental wealth is in the top $1 \%$ group. When children are eighteen years old, we examine the relationship between the positions of children and parents in their respective wealth distributions. We find a strong and almost linear relationship between the percentile ranks of children and parents, with a rank correlation of 0.39. The likelihood of being in the top $1 \%$ group for an eighteen year old is more than fifteen times higher if the parents are in the top $1 \%$ group. The intergenerational relationship becomes stronger during childhood, and at age 18 when moving into adulthood it is at the same level as the next twenty years in adulthood.

Fourthly, we analyze to what extent childhood wealth predicts adulthood riches. We find a strong non-parametric relationship between the position of the child in the (age specific) wealth distribution when entering adulthood (at age 18) and the position in the wealth distribution nearly three decades later when the child is in midlife (at age 45). The position in childhood is strongly related to the position in adulthood, even conditional on parental position, and the effect is stronger than the effect of parental wealth.

It is difficult to disentangle empirically why childhood wealth is such a strong predictor of future wealth. A reason might be that transfers received in childhood are so large that they may accumulate into significant wealth and wealth inequality in adulthood. Our analysis shows that this is not the case. We also pursue a decomposition analysis in the spirit of Charles and Hurst (2003) by controlling for earnings, education, and portfolio composition of both child and parents, to see if these variables account for the role of childhood wealth. For example, wealth transfers to children may coincide with parental investment in their education or may relax future credit constraints of the child and thereby increase child investments in human capital, implying that the child becomes wealthy in adulthood. The analysis indicates only a limited role for such mechanisms going through education and future earnings. The portfolio composition indicators have some explanatory power, which may point to intergenerational transmission of savings and investment behavior. Finally, we show that childhood wealth (conditional on parental wealth) is strongly correlated with future wealth transfers, measured by inheritances when parents die.

Our findings indicate that the intergenerational transmission of wealth is not simply a function of parental wealth, but also of parental behavior starting early in childhood. Wealth in childhood is mainly due to transfers. It is likely that these early transfers are markers for parents who are focused on their children's financial well-being, and their importance in predicting future wealth 
may operate through correlation with subsequent transfers and transmission of a range of behaviors that may come with asset ownership, such as saving propensity and investment patterns.

The remaining part of the paper is organized as follows. Section 2 provides information about legal and institutional rules in Denmark, Section 3 describes the data, and Section 4 describes the empirical results. Finally, Section 5 offers concluding remarks.

\section{Institutional framework}

In Denmark, it is possible for children to own assets but only adults - defined as individuals of legal age, which is eighteen years or older - may borrow.

Wealth observed early during childhood is unlikely to stem from labor income of the child because of the Danish labor market regulations. Children under thirteen years old may not work for an employer with the exception of participation in certain cultural activities approved by the police, such as theatre, circus, radio, television, or work as a photo model. Teens who are thirteen and fourteen years old may perform so-called light work, such as cleaning and newspaper delivery, but only for a limited number of hours. The fifteen-to-seventeen age-group may work in any kind of job that is not dangerous, but most individuals in this age group will still be in the education system.

Wealth unaccounted for by labor income has to stem from wealth transfers, either inter vivos gifts or inheritance. Bequests to children or grandchildren (or parents) above a basic allowanceequal to DKK 264,100 in 2011 - is taxed at a flat rate of 15 percent and 36.25 percent if given to other persons. ${ }^{4}$ Gifts to children and grandchildren above a yearly basic allowance-equal to DKK 58,700 in 2011 - are taxed at the same rate as bequest, while gifts to non-relatives are treated as personal income and taxed accordingly. Hence, inter vivos transfers to children may be tax motivated. For example, making gifts below the basic allowance may be a strategy to avoid inheritance taxation. ${ }^{5}$

Denmark also has tax-favored rules for so-called child savings accounts (funds may be on deposit accounts but may also be placed in securities). Only parents, grandparents, etc., can make deposits. The capital income from this type of savings is tax exempt. The political goal of this special tax

\footnotetext{
${ }^{4}$ Exchange rates are approximately DKK 8.5 per GBP, DKK 7.5 per EURO, and DKK 5.5 per USD in 2011.

${ }^{5}$ It may also reduce capital income taxation. For example, stock income in Denmark is taxed separately from other income in a progressive tax scheme with two tax brackets; the tax rates are $27 \%$ and $42 \%$ in 2011 . By transferring wealth to the child, capital income that would otherwise be taxed at the high rate may now be taxed at the low rate (it would be illegal for parents to transfer funds to the children and later transferring it back to themselves in order to save taxes).
} 
scheme is to teach young people to save money and to have sensible financial behavior. In line with this goal, funds in an account cannot be withdrawn until at least seven years after putting the money in the account. It is only possible to put money in the account until the child is fourteen years old, and the amounts that may be put in the accounts are small. For example, in 2011 a maximum of DKK 3,000 can be deposited in the account of a child per year, and the total amount a child can receive on the account is limited to DKK 36,000.

\section{Data}

Our analysis is based on individual wealth data available at Statistics Denmark. The data contains the aggregate value of assets and liabilities in the period 1983 to 2011, and from 1995 and onwards it is also possible to obtain complete portfolio information with respect to the value of bonds, stocks, cash in banks, real estate, mortgage loans, and the sum of other loans. The wealth data is based on administrative tax return records from the Danish Tax Agency (SKAT), which collects information about the values of asset holdings and liabilities of all individuals measured the last day of the year.

Most of the wealth components are third-party reported. ${ }^{6}$ Information about the value of financial assets and liabilities at the end of the year is reported to the tax authorities by banks, other financial institutions, and some government institutions, while the cash value of real estate is assessed by the tax authorities, based on detailed information of the real estate, and used for taxation of the imputed rent. ${ }^{7}$ Third-party reported values of assets include all deposits, stocks, bonds, value of real estate, and deposited mortgages. Pension funds are not part of the data, which is also the case in the US study by Charles and Hurst (2003), but when measuring wealth in childhood, it is not relevant. Third-party reported values of liabilities include debt in financial institutions, mortgage credit debt, credit and debit card debt, deposited mortgage debt, student debt and debt in The Mortgage Bank (a public institution), debt to financial corporations, debt to the Danish municipalities, and other liabilities such as unpaid taxes and mortgage debt, which are

\footnotetext{
${ }^{6}$ Information on wealth was originally used to compute the wealth tax, which was in place until 1996. Today it is used by the tax agency to cross check if the reported income level is consistent with the change in net-wealth during the year under the assumption of a given estimated consumption level. A recent study of tax evasion behavior by Kleven et al. (2011) finds only small differences between the third-party reported income items and the corresponding items on the final tax return. This indicates that the third-party reported information of the Danish Tax Agency is of a very high quality.

${ }^{7}$ The public values of real estate are normally below market value. For each year, we adjust the values upwards following Leth-Petersen (2010) by using the average relative difference between selling price and the public value of real estate traded that year.
} 
not deposited.

Until 1996, Denmark had a wealth tax, and taxpayers had to self-report car values, boat values, caravan values, title deed of cooperative dwellings, premium bonds, cash deposits, stocks (both listed and non-listed thereby including privately held companies), and private debt. These components are not included in the computations after 1996, when the wealth tax was abolished. Until 1996 the value of stocks was self-reported, while afterwards it became third-party reported by banks and financial institutions (excluding non-listed stocks). The registration of the company value of self-employed has changed several times, but has stayed unchanged since 1997, where assets and liabilities of the firm were registered separately and included, respectively, in the assets and liabilities of the owner. More details on the data on wealth may be found in Leth-Petersen (2010) and Boserup, Kopczuk, and Kreiner (2015).

The administrative data provides a good measure of individual wealth, but contains no direct information about wealth transfers (inter vivos transfers and bequests), which will have to be inferred using indirect methods.

Every citizen in Denmark is assigned a unique personal identification number at birth and the identification numbers of the mother and the father are registered for all Danes born from 1960 and onwards. This enables us to link wealth information across generations and to link the wealth data to other registers containing birth year, education, and income.

In the empirical analysis, we consider mainly two samples. First, we analyze a pooled crosssectional data set (PCD) containing all individuals who are 1-40 years old in the years 2000-2011 and have parents who are alive. We stop at age 40, which for year 2000 corresponds to the first cohort where parents are systematically registered, i.e., the cohort born in 1960. We consider oneyear age groups with information pooled over the years, corresponding to pooling 12 cohorts for each one-year age group. This gives on average close to 650 thousand observations in each one-year age group of the children. The second sample is a panel data set (PD) where we follow the cohort of individuals who are born in 1965, and where both parents are alive in 2011. This sample allows us to study the relationship between childhood wealth and wealth in adulthood. We follow these individuals from 1983 to 2011, corresponding to ages of 18 through 46. Tables A1 and A2 provide summary statistics for the two samples. 


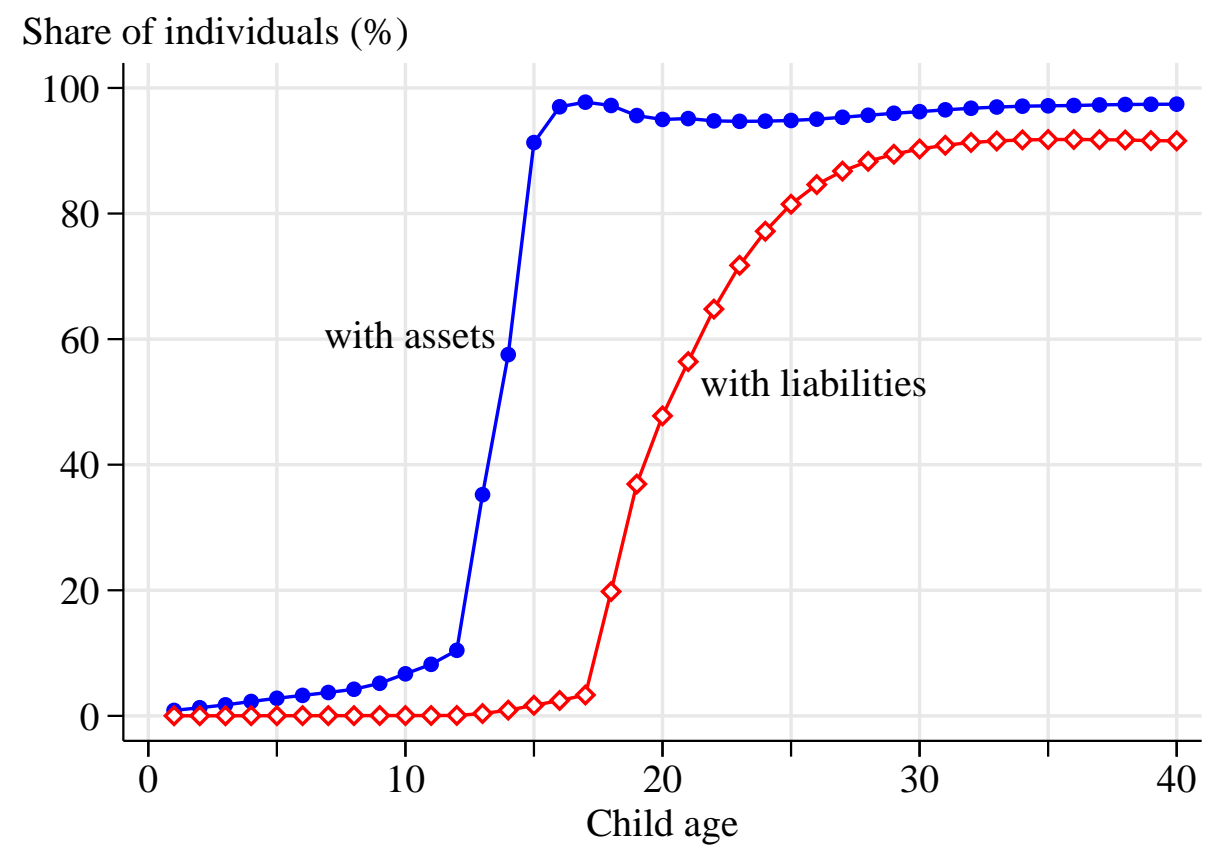

Figure 1: Ownership of assets and liabilities by child age

Notes: The figure shows the share of the children owning assets and the share of children having liabilities within each one-year age group in the PCD sample. The PCD sample and the definitions of assets and liabilities are described in Table A1.

\section{Empirical results}

We divide the description of the empirical results into subsections addressing each of the following questions: How many children own assets and how is childhood wealth distributed? What are the sources of childhood wealth? To what extent is childhood wealth related to parental wealth? Does wealth in childhood predict adulthood riches and, if so, why?

\subsection{How many children own assets and how is childhood wealth distributed?}

Figure 1 displays the share of individuals who own assets and the share of individuals with liabilities in each one-year group in the PCD sample. These two relationships show that both asset ownership and loan take-up increase with age. A little less than 1 percent of one-year olds own assets. The asset ownership share rises gradually to 10 percent at age 12, after which it increases sharply to 91 percent at age 15; only slightly below its level in adulthood, which is stable around 97 percent.

The loan take-up curve confirms that almost nobody has debt before the age of 18, reflecting that only individuals of legal age may borrow as described in Section 2. Indebtedness jumps up to 20 percent for individuals at age 18 , increases gradually up to around 90 percent at the age of 30 , 
and is then nearly flat up until the age of 40 .

In Figure 2, we look in greater detail at asset ownership. Panel A shows the share of each age group having bank deposits, securities, and real estate, respectively, while panel B shows asset composition for each age group. In childhood, between ages of 1 and 12, all wealth is in bank deposits and securities with ownership rates increasing gradually from 1 to 10 percent for bank deposits and from 1 to 4 percent for securities. For these age groups, securities make up 70-75 percent of total wealth. Note also that the ownership rate of bank deposits in panel A mirrors the curve for all assets in Figure 1 with the same sharp increase from the age of 12 to 15, reflecting that children start participating in the labor market at this age (see Section 4.2). Real estate ownership is not relevant before adulthood, but during adult life it increases and becomes the single most important asset, accounting for more than 80 percent of the total asset value in the thirties.

In Figure 3, we present information about the distribution of wealth by showing the median and values of various percentiles in the age-specific wealth distribution. Given skewness of the distribution, we show results on a log scale and censor the graph from below at DKK 1,000. Even the 99th percentile is zero for one-year olds reflecting that a little less than one percent have positive wealth. ${ }^{8}$ Top percentiles are increasing during childhood with the fastest growth occurring during early childhood. At age 10, percentile 99 equals DKK 100 thousand and when formally becoming adult according to Danish law at age 18, percentile 99 is DKK 300 thousand. At this point in life, the average wealth level of top $1 \%$ corresponds to almost five times GDP per capita while the average wealth of top $0.1 \%$ corresponds to more than 20 times GDP per capita. Lower wealth percentiles increase when people are in their teens, but then the median becomes negative in the twenties when many individuals are students and it is possible to borrow, before becoming positive again when people are around 30 .

The differences across age groups in the PCD sample may in principle just reflect time variation rather than life-cycle variation because of the pooling of information over several years and generations. In Appendix B, Figures B1 and B2, we redo Figure 1 and Figure 3 for each of the twelve years used in the sample. The graphs reveal a little business cycle variation over time, but during childhood the differences are small compared to the variation across ages and the differences between percentiles in the age-specific distribution.

\footnotetext{
${ }^{8}$ The wealth share of top $1 \%$ is therefore 100 percent. The average wealth level of the top $1 \%$ group of one year olds is DKK 28 thousand. This amount corresponds to GPB 3,300, EURO 3,700 and USD 5,100 when using 2011 exchange rates approximately equal to DKK 8.5 per GBP, DKK 7.5 per EURO, and DKK 5.5 per USD. It can also be compared to, for example, the GDP per capita of 196 thousand in 2011 and an average wealth level of DKK 357 thousand for 40 year olds in our data.
} 
A. Share of individuals owning assets (\%)

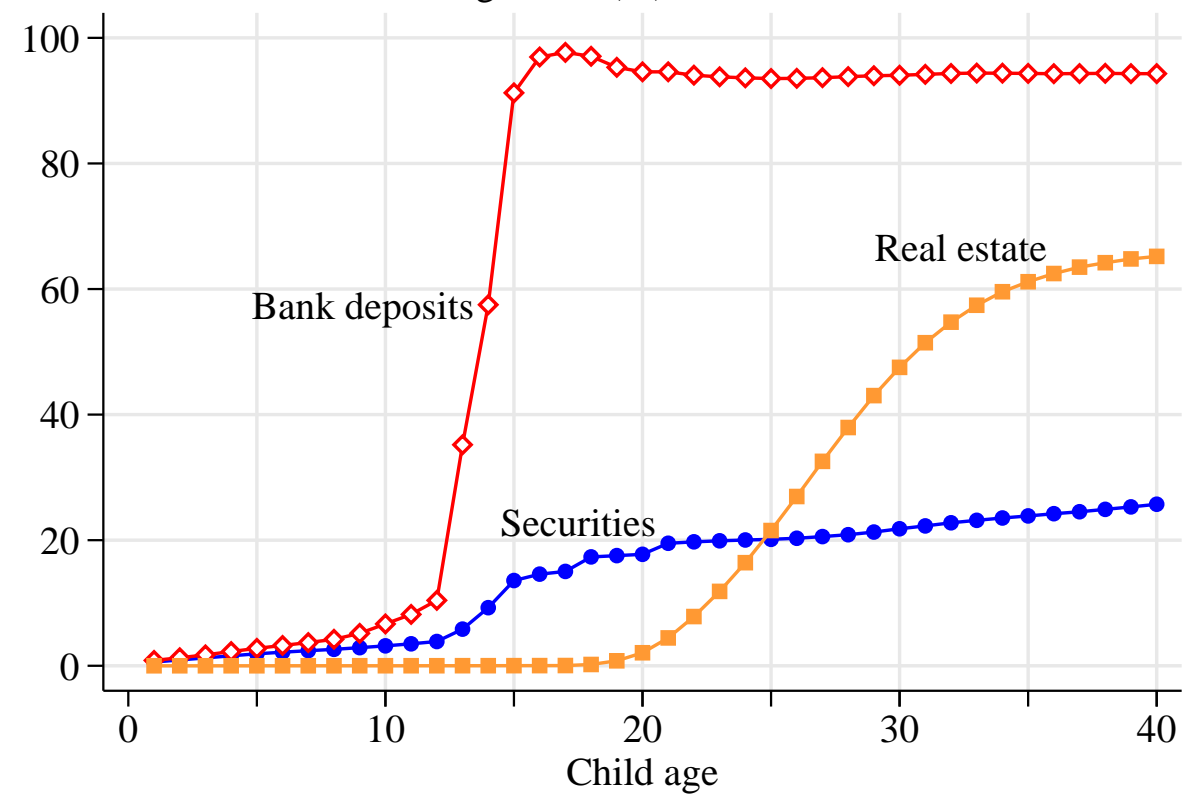

B. Cumulative share of total assets (\%)

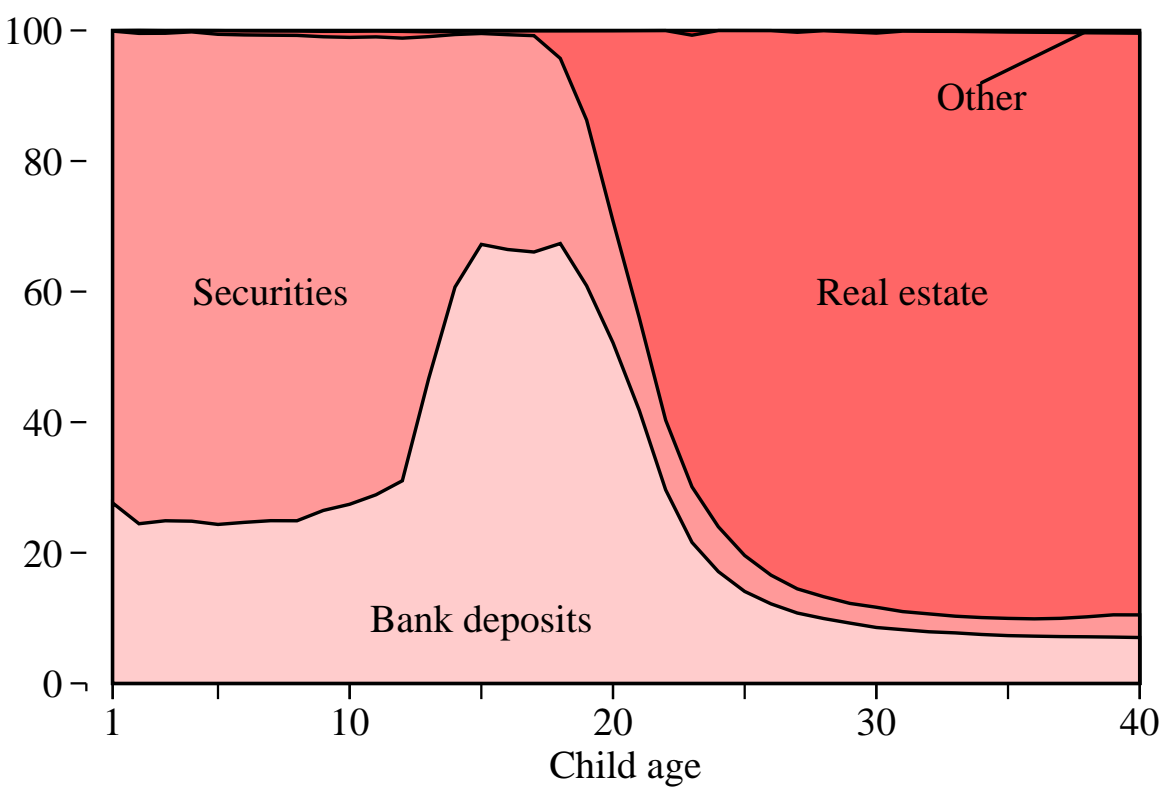

Figure 2: Asset ownership by child age

Notes: Panel A shows the share of the children within each one-year age group in the PCD sample who have bank deposits, securities, and real estate, respectively. Panel B shows for each one-year age group in the PCD sample the aggregate value of each type of asset relative to the total value of assets owned by the age group. The PCD sample and the definitions of assets and liabilities are described in Table A1. 


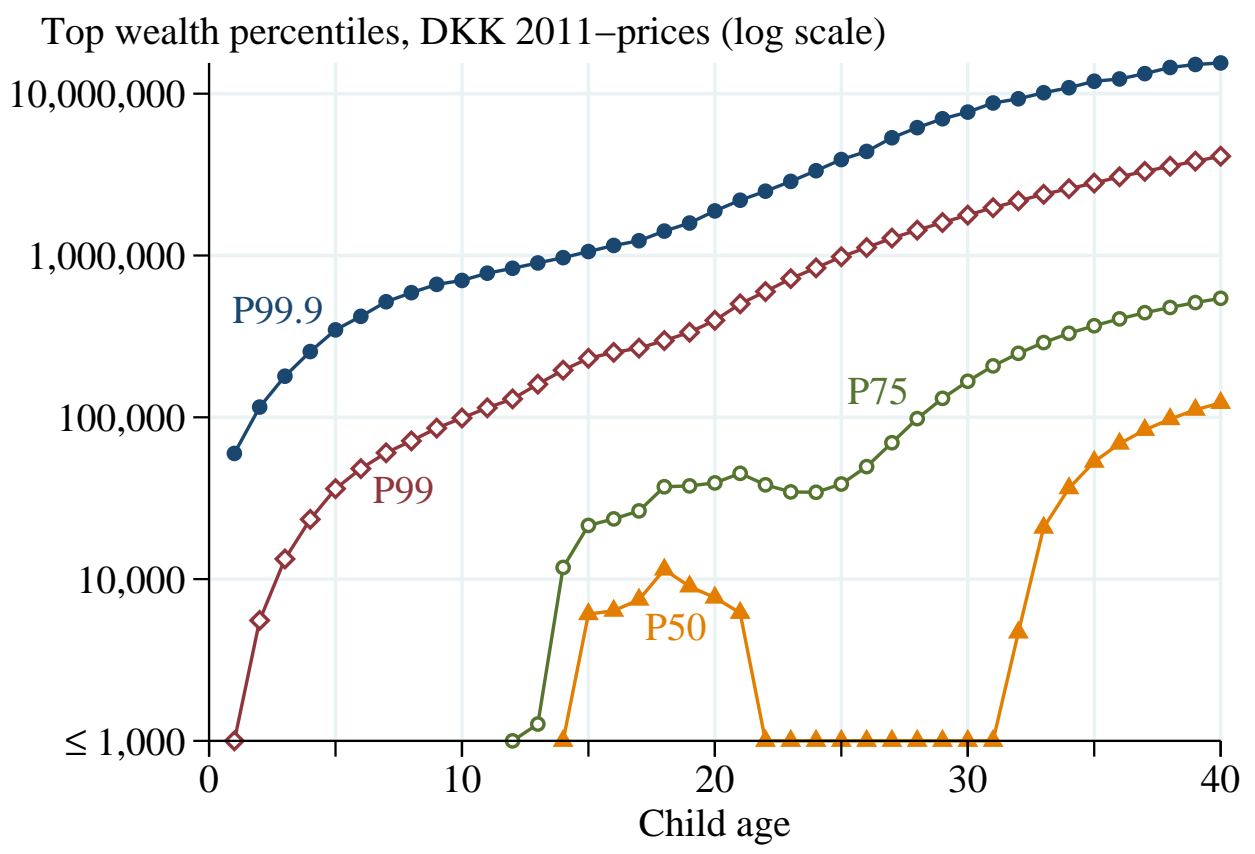

Figure 3: Wealth levels in top wealth groups by child age

Notes: The figure shows the value of median, 75th, 99th, and 99.9th percentiles in the age-specific wealth distribution in the PCD sample. It is derived by first computing the percentiles for each of the years 2000-2011 and then taking the average value. Wealth levels are shown on a log scale and quantiles are censored from below at DKK 1,000. The PCD sample and the definition of wealth are described in Table A1.

\subsection{Sources of child wealth}

The underlying sources of wealth are labor income and transfers. By definition, wealth holdings of an individual at any given point in time is equal to the accumulated value (including return on savings) of labor income plus the accumulated value of wealth transfers minus the accumulated value of expenditures over the life span of the individual up to the time of measurement. As described in Section 2, the legal framework in Denmark prevents children from working before turning thirteen years old. This implies that the source of wealth until this age can only be wealth transfers. This is supported by Figure 4, which shows for all ages in the interval 1-20 years the average earnings of the top $1 \%$ wealth group and of those not in the top $1 \%$ group. Wage income is virtually zero for both groups until the age of thirteen. From age thirteen until age eighteen, mean earnings rise up to a level around DKK 40 thousand, which is around 1/5 of GDP per capita. Notice also that during this period in life, children who are not in the top $1 \%$ group actually earn more in the labor market than the wealthy children.

The increase in labor market participation coincides with a strong increase in the share of chil- 


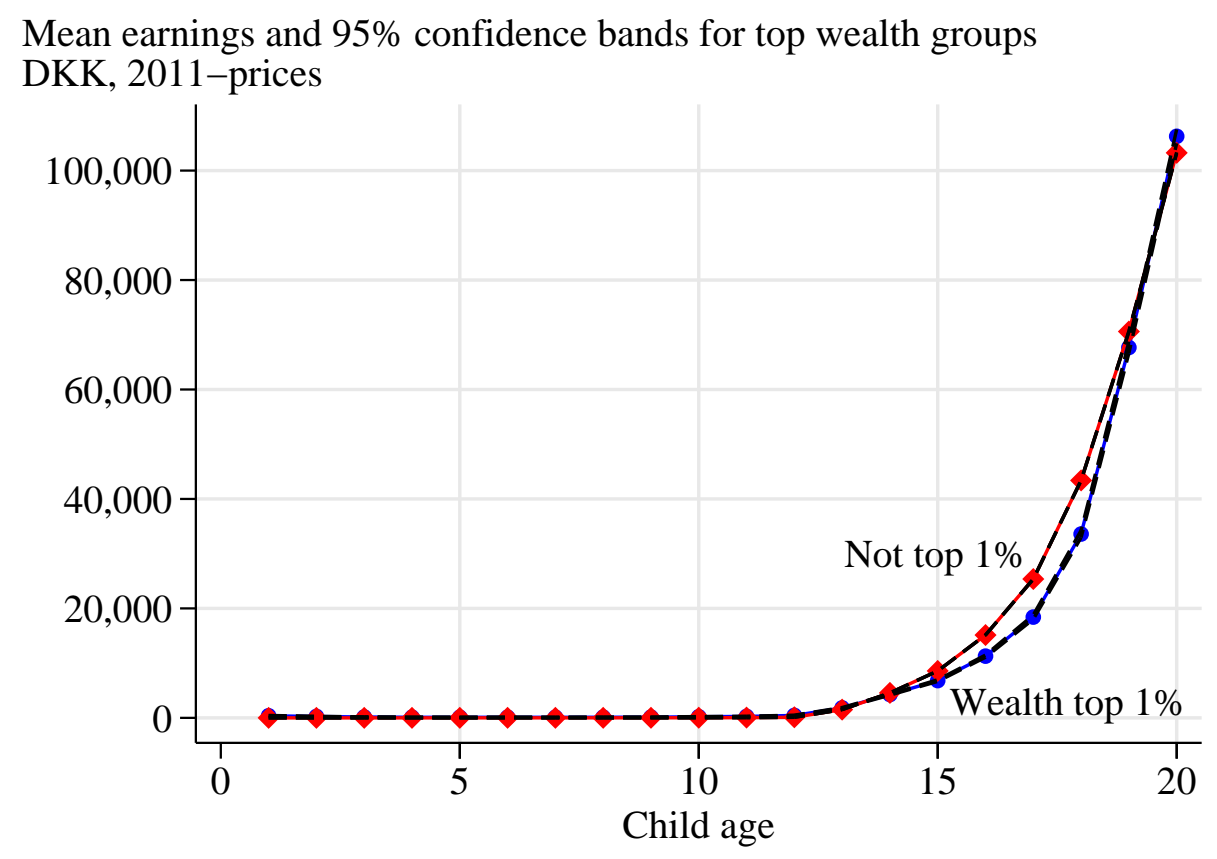

Figure 4: Mean earnings by child age

Notes: The figure shows the mean earnings level for individuals in the top $1 \%$ wealth group and for individuals not in the top $1 \%$ wealth group in the PCD sample. The black dashed lines represent $95 \%$ confidence bounds using robust standard errors. The PCD sample is described in Table A1.

dren with positive wealth holdings (see Figure 1). In Table 1, we provide a more systematic account of the share of wealth that may be accounted for by earnings and wealth transfers, respectively. The table is constructed by computing for each child, at the age reported in the table, the difference between the level of wealth at this age and the present value of earnings up to this age. Under the assumed rate of return and if children do not spend out of accumulated wealth in childhood, this residual represents wealth not explainable by earnings and equals the present value of wealth transfers. To the extent that the child does have spendings, the residual is a lower bound of the value of transfers received, and we therefore censor it at zero. The table shows the sum of these wealth residuals expressed as the share of aggregate wealth of the individuals in the age group, thereby obtaining a lower bound estimate of the share of wealth accounted for by transfers. This is done for all ages up to adulthood and using different real interest rates $(0 \%, 3 \%$, and $6 \%) .{ }^{9}$

As expected, the table indicates that earnings could play an increasingly larger role for wealth accumulation during the teenage years. Still, the unexplained component of wealth is large. For an average person, the estimated lower bound of the share of wealth transfers out of total wealth

\footnotetext{
${ }^{9}$ Discounting is on top of inflation that is already accounted for by adjusting monetary variables using the CPI deflator throughout.
} 
Table 1: The lower bound for the share of transfers in overall wealth for each age group

\begin{tabular}{|c|c|c|c|c|c|c|c|c|c|}
\hline \multirow[b]{2}{*}{ Age } & \multicolumn{3}{|c|}{$\begin{array}{c}\text { A. All } \\
\text { Rate of return }\end{array}$} & \multicolumn{3}{|c|}{$\begin{array}{c}\text { B. Top } 1 \% \\
\text { Rate of return }\end{array}$} & \multicolumn{3}{|c|}{$\begin{array}{l}\text { C. Top } 0.1 \% \\
\text { Rate of return }\end{array}$} \\
\hline & $0 \%$ & $3 \%$ & $6 \%$ & $0 \%$ & $3 \%$ & $6 \%$ & $0 \%$ & $3 \%$ & $6 \%$ \\
\hline$\leq 12$ & 100 & 100 & 100 & 100 & 100 & 100 & 100 & 100 & 100 \\
\hline 13 & 91 & 91 & 91 & 100 & 100 & 100 & 100 & 100 & 100 \\
\hline 14 & 80 & 80 & 80 & 99 & 99 & 99 & 100 & 100 & 100 \\
\hline 15 & 73 & 72 & 72 & 98 & 98 & 98 & 100 & 100 & 100 \\
\hline 16 & 63 & 62 & 62 & 97 & 97 & 97 & 100 & 100 & 100 \\
\hline 17 & 53 & 53 & 52 & 95 & 95 & 95 & 100 & 99 & 99 \\
\hline 18 & 49 & 48 & 47 & 92 & 92 & 91 & 99 & 99 & 99 \\
\hline Observations & \multicolumn{3}{|c|}{389,669} & \multicolumn{3}{|c|}{3,896} & \multicolumn{3}{|c|}{390} \\
\hline
\end{tabular}

Notes: Calculated using the PCD sample described in Table A1. The table is constructed by computing for each child, at the age reported in the table, the difference between the level of wealth at this age and the present value of earnings up to this age, using the real rate of returns in the table. This residual equals the present value of wealth transfers if children do not spend out of accumulated wealth in childhood. The residual is therefore a lower bound of the value of transfers received and is censored at zero. The table reports the sum of the wealth residuals expressed as a share of aggregate wealth of the individuals in the age group.

reported in panel A decreases gradually from 100 percent at age 12 to around 50 percent when moving into adulthood. The rate of return has almost no role to play for these estimates. Panel B shows the same results for individuals with wealth in the top $1 \%$ group. Here, the minimum share of wealth explained by transfers also falls somewhat as children age, but the estimates show that wealth transfers still explain at least 91 percent of the accumulated wealth when these individuals are 18 years old. For the top $0.1 \%$, virtually all wealth has to be explained by transfers as illustrated in panel $\mathrm{C}$.

Children may receive inter vivos transfers and/or bequests, and realistically these transfers come from older family members. In early childhood, it is unrealistic to expect that wealth stems from bequests related to parental death (at the age of 18, both parents are alive for 95 percent of children). However, it may come from bequests related to death of one of the grandparents. In Figure 5, we redo the analysis in Figure 1, this time showing the share of individuals with positive net-wealth. Panel A shows the share by age for the full sample and for a restricted sample that for each age group only includes children where all four grandparents are alive. The two graphs are nearly identical indicating that bequests from grandparents are not the driving force behind ownership of wealth of children.

In order to also obtain a casual estimate of the role of bequests, we follow the event analysis 
A. Share of individuals (\%) with wealth > 100 DKK

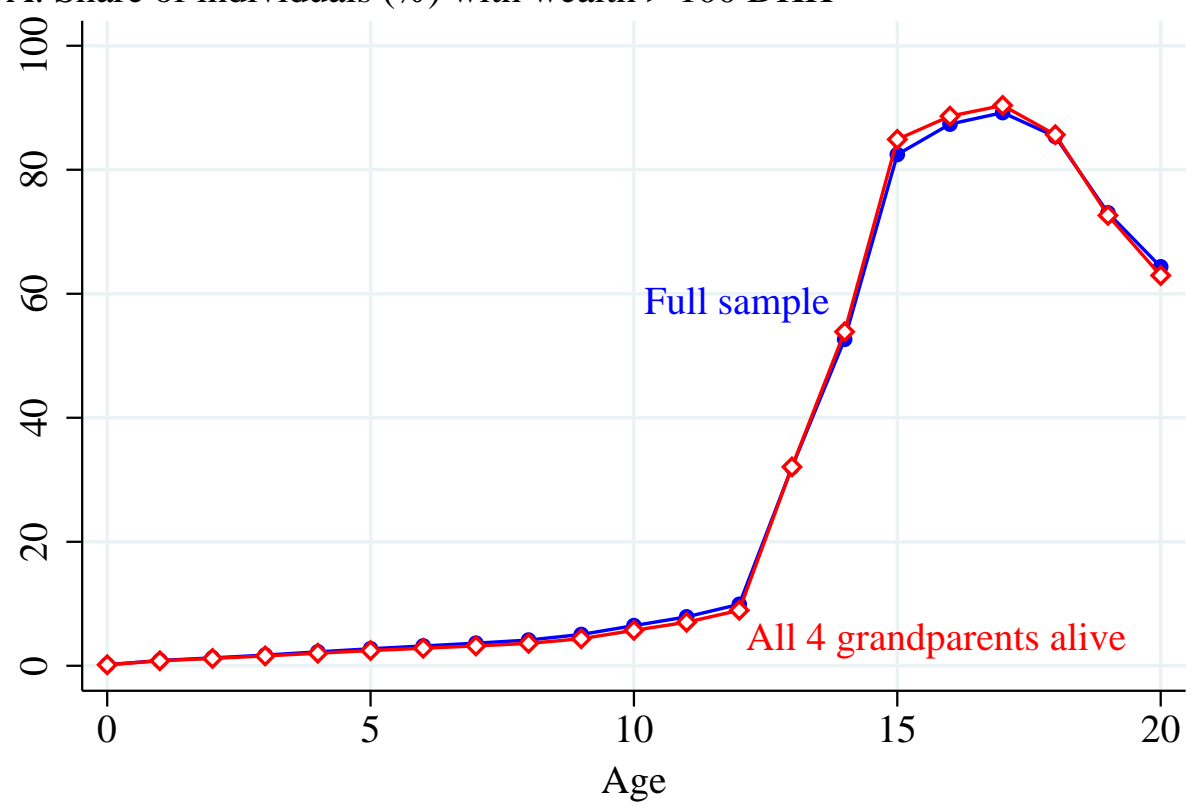

B. Share of individuals $(\%)$ with wealth $>100 \mathrm{DKK}$

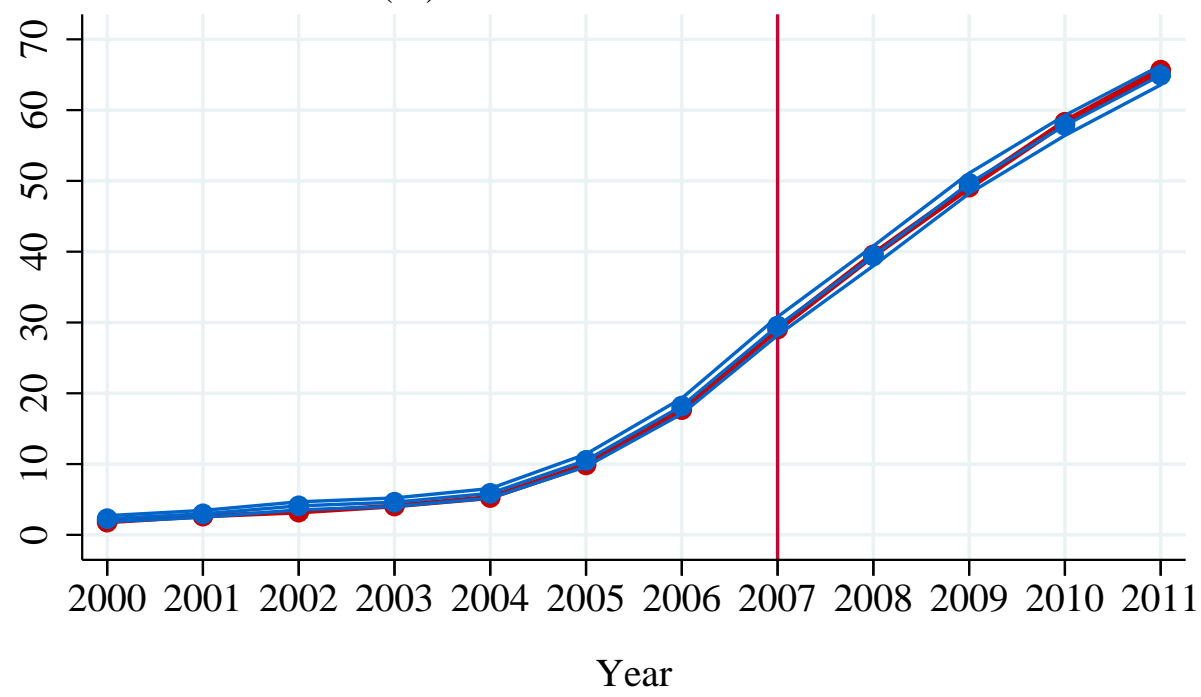

- Control group — Treatment group

Figure 5: Childhood wealth and the role of grandparents

Notes: The figure is based on the PCD sample described in Table A1. The top panel contrasts the share of the population with positive wealth for the full PCD sample and for those that have all grandparents alive.

The lower panel shows the event study following grandparental death. The sample consists of children who are between the ages of 7 and 15 in 2007 with no grandparental deaths between 2000-2006, and exactly one grandparent left on either paternal or maternal side (and 0, 1, or 2 living grandparents on the other side). Children in the treatment group are those whose father or mother lose their last living parent in 2007. Children in the control group do not lose a grandparent in 2007. 
approach in Boserup, Kopczuk, and Kreiner (2016) and study the development of child wealth around the death of grandparents. The result is displayed in panel B. In the analysis, we focus on a balanced panel of individuals who are 0-8 years old in 2000, who do not lose any grandparents in 2000-2006, and who have exactly one remaining grandparent in either paternal or maternal branch as of 2006 (they may have any number of living grandparents in the other branch). We define the treatment group as those children who lose the last remaining grandparent in either maternal or paternal branch in 2007, with the rest of the sample in the control group. This approach is motivated by the fact that bequests in Denmark normally only occur when both individuals in a couple are dead (Boserup, Kopczuk, and Kreiner 2016). At the event time, children are 7-15 years old. Since children on average are older in the treatment group where grandparents die, we reweigh the sample so that the age distributions of the children are the same in the two groups. In all years, both before and after the event, the graph shows that the share of individuals with positive wealth is almost at the same level for the two groups. This also indicates that bequests from grandparents are not the driving force behind the wealth of children. In Appendix $\mathrm{C}$, we provide additional analyses pointing to the same overall conclusion.

All of this leaves inter vivos transfers as the only remaining main source that can explain large wealth in childhood. We cannot observe such transfers directly in the data though. Hence, in order to go beyond the mere assertion, we provide evidence that they do take place by relying on tax incentives. Inter vivos transfers may well be tax motivated as described in Section 2, but it is difficult to identify this effect precisely because of the existence of different tax motives at the same time and because non-taxable wealth transfers do not have to be reported to the tax authorities. Still, we can investigate whether wealth transfers are influenced by the tax scheme for gifts by taking advantage of the fact that gifts below a basic allowance are non-taxable. The marginal tax rate jumps from 0 to 15 percent (36.25 percent for non-relatives) when the transfers received exceed the basic allowance. Heterogeneity in wealth levels of donors and/or in their preferences for giving generate variation in gifts, and the presence of the discontinuity in marginal incentives implies theoretically that there should be bunching in the distribution of received transfers across recipients, like with any other continuous decision analyzed in the "bunching" literature. We formalize this notion with a simple model in Appendix D. ${ }^{10}$

A challenge when trying to identify empirically whether individuals bunch together at the tax

\footnotetext{
${ }^{10}$ Our interest here is only in showing that tax-motivated transfers exist (proved using bunching evidence) rather than estimating the elasticity of the response as in Saez (2010). Obtaining a reliable estimate of the tax elasticity of gifts would require a better measurement of transfers.
} 
threshold for gifts is that inter vivos transfers are unobservable and that imprecise measurement may reduce the observed bunching considerably (Chetty 2012). In particular, in our data, we only observe the stock of wealth and not the flow of gifts. To obtain a reasonably reliable measure for the study of bunching, we register the first time an individual has positive wealth (hence wealth at that point is both the stock and its annual change) and measure the distance to the threshold at which the gift tax starts to apply (the yearly basic allowance is equal to DKK 58,700 in 2011 as described in Section 2). We focus on the age group 1-12 years where asset ownership cannot be due to own earnings. We then plot the number of individuals in bins in order to look for bunching around the threshold, which is evidence that the behavior underlying wealth transfers responds to the tax incentive (Saez 2010). The result is shown in Figure 6. Since the basic allowance applies for each person giving a gift, we look for bunching both around the level of wealth corresponding to one person giving the maximum untaxed amount and around the level corresponding to two people giving the maximum untaxed amount (say both parents or two grandparents). Panels A and B provide evidence of bunching in both cases demonstrating that some of children's wealth is due to inter vivos transfers. ${ }^{11}$

\subsection{Relationship between childhood wealth and parental wealth?}

In this section, we explore the intergenerational relationship between positions of children and parents in the wealth distribution using the PCD sample. We start in panel A of Figure 7 by examining non-parametrically the relationship between the percentile rank of children's wealth at age 18 and the percentile rank of their parents' total wealth observed at the same time. The rank of each individual is computed in the child age-year specific wealth distributions in order to control for life-cycle changes in wealth as well as changes over time. ${ }^{12}$ Panel A shows a binned scatter plot where child-parents pairs are divided into 100 groups according to the percentile rank of parental wealth and showing for each percentile the mean rank of children. The child mean rank estimates are very precise as shown by the small 95 percent confidence interval at each point estimate.

The graph reveals a strong and almost linear relationship between children and parents, except

\footnotetext{
${ }^{11}$ It also naturally indicates that tax incentives have a role to play in the decision-making underlying these transfers, in line with evidence of tax-motivated inter vivos transfers in adulthood (e.g., Bernheim, Lemke, and Scholz 2004, Joulfaian 2005, and Kopczuk 2007).

${ }^{12}$ The rank transformation has other advantages. For example, it is unaffected by monotone transformations of the underlying data and is therefore a very robust measure. It also works well with zero and negative observations that are common in wealth data. In that respect, note that we randomize the rank within individuals having the exact same level of wealth, which is particularly important for young children who have zero wealth.
} 
A. Basic allowance

Number of children

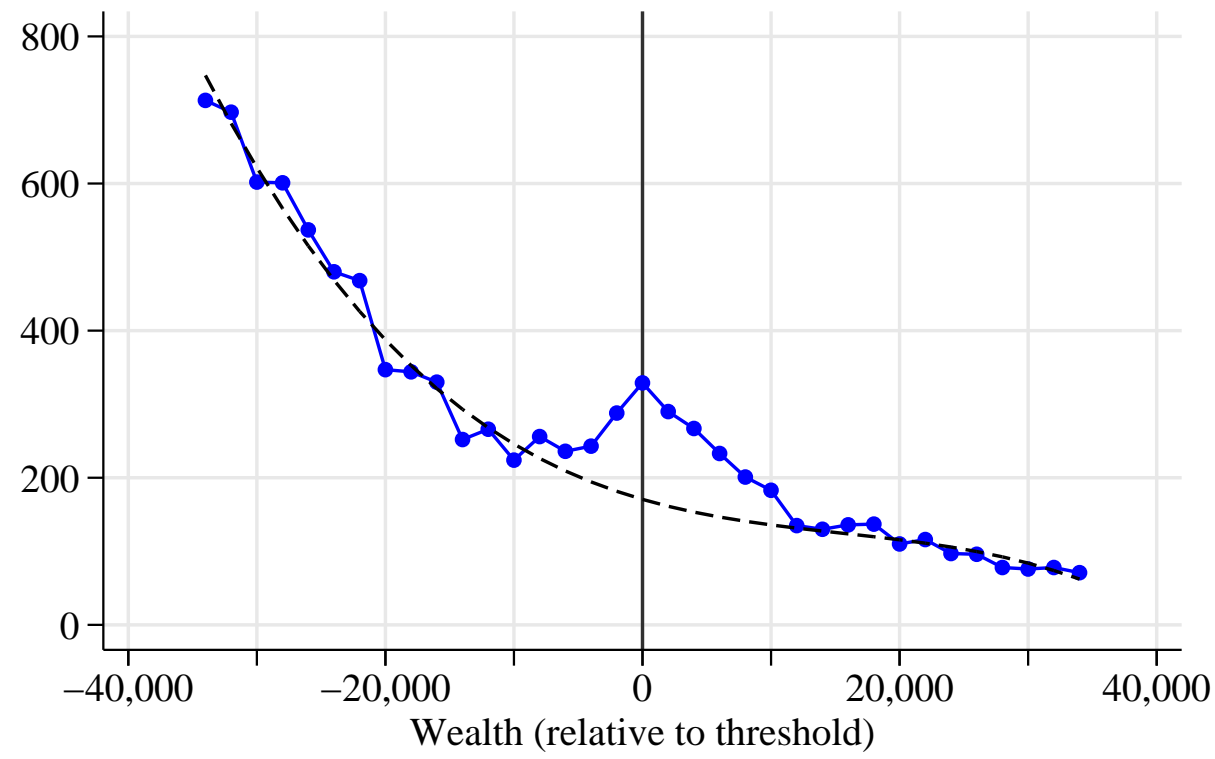

B. Double basic allowance

Number of children

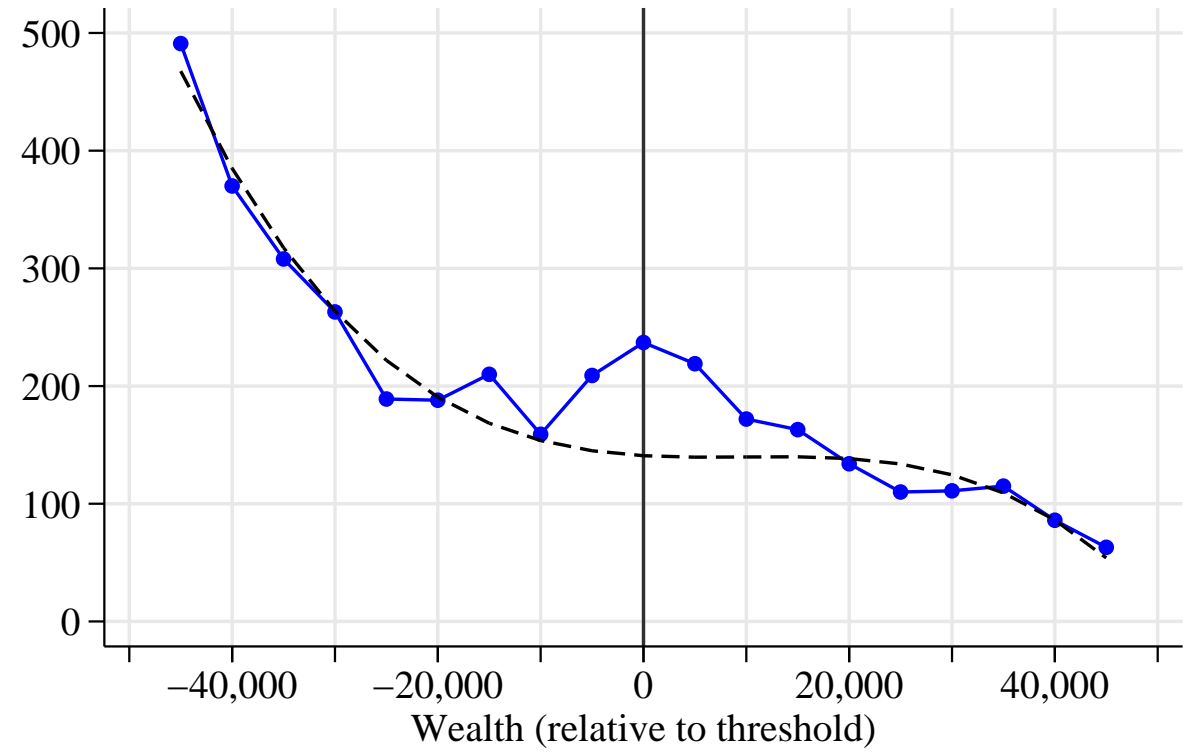

Figure 6: Bunching at the exemption level of gift taxation

Notes: These figures are based on a subsample of the PCD sample. For all individuals who are between 1 and 12 years old, we register the first time an individual has positive wealth and then measure the distribution of these amounts across individuals relative to the basic allowance that applies to inter vivos transfers/gifts in that year (demarcated by the vertical line at 0 ). Gift taxation applies if an individual gives an amount beyond the basic allowance as described in Section 2. In panel B, we consider the distribution around the level corresponding to two times the basic allowance, reflecting that the basic allowance may be exploited by, e.g., both parents or by two grandparents. Each point in panel A (panel B) shows the number of observations in bins of DKK 2,000 (DKK 5,000). The dashed line beneath the empirical distribution is a third-degree polynomial fitted to the empirical distribution excluding the points in $[-10,000 ; 10,000]$. The PCD sample and the definition of wealth are described in Table A1. 
A. Children age 18

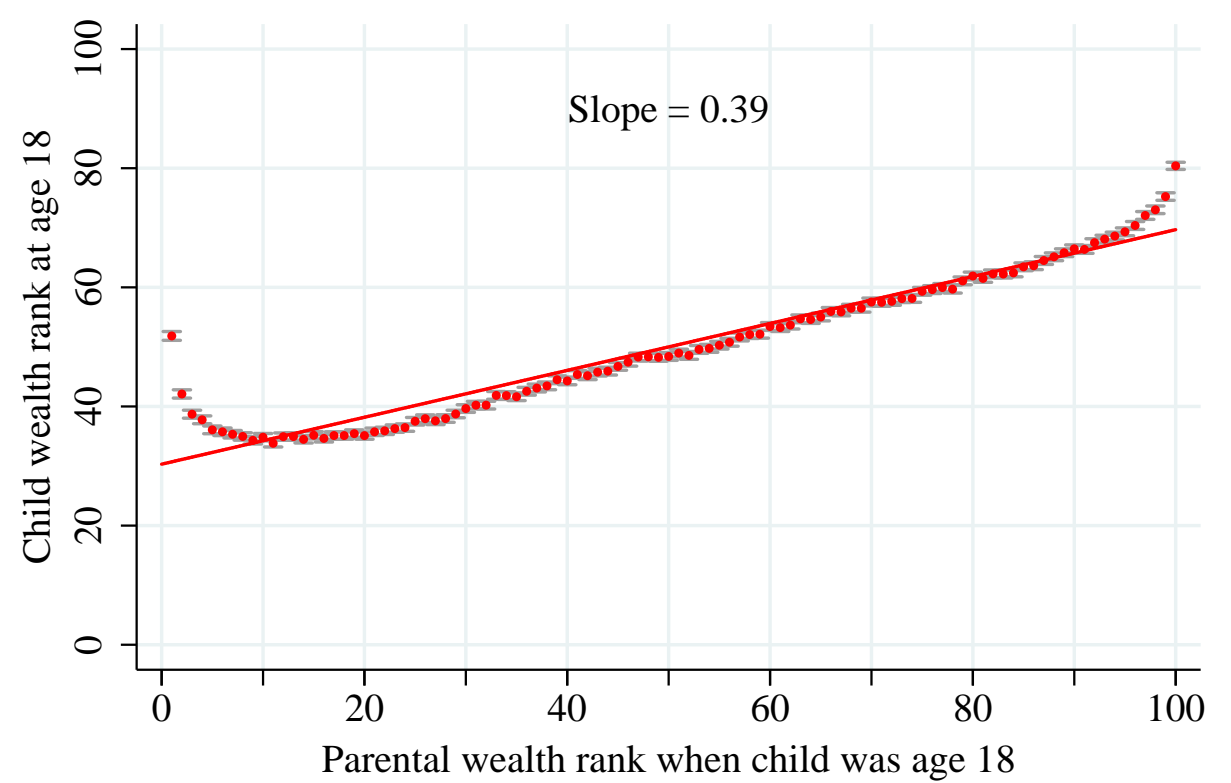

Mean child wealth rank $• \quad 95 \%$ conf. interval $\longmapsto \quad$ OLS fit -

B. Children age 1

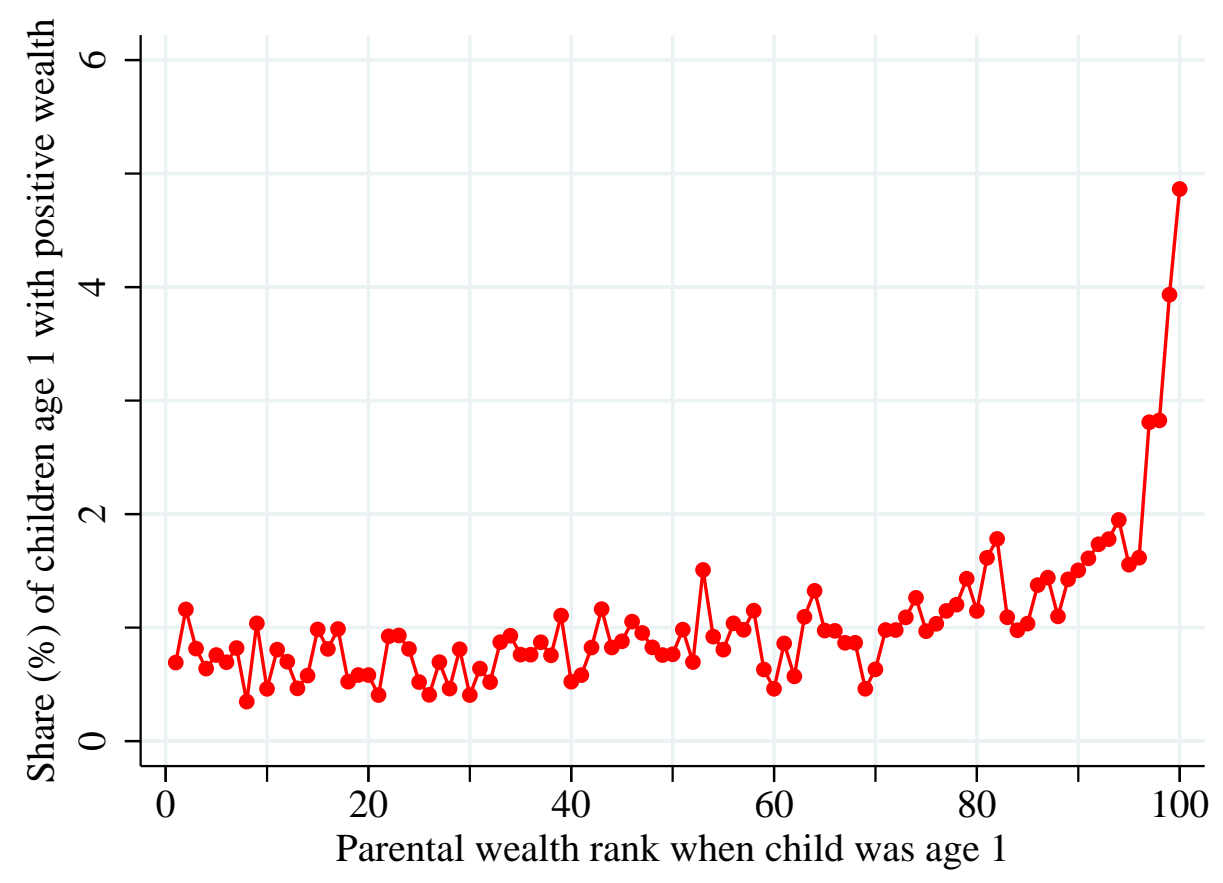

Figure 7: Relationship of parental and childhood wealth

Notes: The figure relies on the PCD sample described in Table A1. Child and parental ranks are measured within child age cohorts and year. Panel A shows the average rank of a child at age 18 conditional on parental rank, together with $95 \%$ confidence intervals and the OLS estimate of the slope based on individual level data. Panel B shows the share of children owning any wealth at age 1 , conditional on parental wealth rank. 
at the bottom of the parental wealth distribution. ${ }^{13}$ Children of parents in percentile 10 are on average in percentile 35, while children of parents in percentile 90 on average are in percentile 66. The intergenerational relationship is stronger at the very top of the distribution. From percentile 99 to percentile 100 in the parental distribution, the average position of children goes up by 5 percentiles. The rank correlation, corresponding to the overall slope in the diagram and estimated from an OLS regression of child rank on parental rank on the individual level data, equals 0.39. ${ }^{14}$

The evidence displayed in panel B of Figure 7 reveals an intergenerational relationship already when children are one year old. Only around one percent of children own any wealth this early in life, implying that for them the percentile rank measure is not very informative. Instead, we plot on the y-axis the share of children owning any assets at age 1 for each percentile rank group of parents. For the bottom 80 percent of the parental distribution, the share of children owning any assets is between 0.5 and 1 percent and almost unrelated to parental wealth. Higher in the distribution though the curve bends up with two percent of children owning assets at percentile 80-95 of parents, three percent at percentile 97, and five percent at percentile 100.

Together, the two diagrams in Figure 7 reveal a strong relationship between childhood and parental wealth levels. To see how the intergenerational relationship develops as a function of child age, we examine the relationship between children and parents in the probability of being in the top $1 \%$ group (as already explained, the rank measure is not very useful when looking at wealth in early childhood). We do this in Figure 8 by showing estimates from a regression of a top $1 \%$ child wealth dummy on a top $1 \%$ parental wealth dummy for each age group of the children. The intergenerational relationship becomes stronger as a function of child age up to around the time when the child moves into adulthood at age 18. For one year old children, the propensity to be in the top $1 \%$ group is 2.4 percentage points higher if parents are in the top $1 \%$ group. This implies that the likelihood of becoming a top $1 \%$ child is 3.4 times higher if the parents are in the top $1 \%$ group compared to the unconditional probability (i.e., $2.4 \%+1 \%$ divided by $1 \%$ ). At age 18 , the likelihood of being a top $1 \%$ child is more than fifteen times higher than the unconditional probability. Interestingly, the intergenerational association peaks when children enter into adulthood at age 18 , and is then almost constant until age 30 , and then declines slightly. ${ }^{15}$

\footnotetext{
${ }^{13}$ The nonlinearity at the bottom of parental distribution probably reflects that the wealth levels of these parents are a bad proxy for their "true" types. Large negative wealth that may reflect involvement in risky investment projects that either have gone wrong or have not paid off yet. Consistent with this hypothesis, we find that self-employed are largely overrepresented in the bottom of the distribution.

${ }^{14}$ The OLS estimate of the slope using only observations in the $10 \%-90 \%$ range is 0.42 .

${ }^{15}$ The top $0.1 \%$ relationship has the same shape as the top $1 \%$ relationship, but the magnitudes are larger. For an 18 year old, the probability of being in the top $0.1 \%$ group is on average 160 times higher than the unconditional
} 


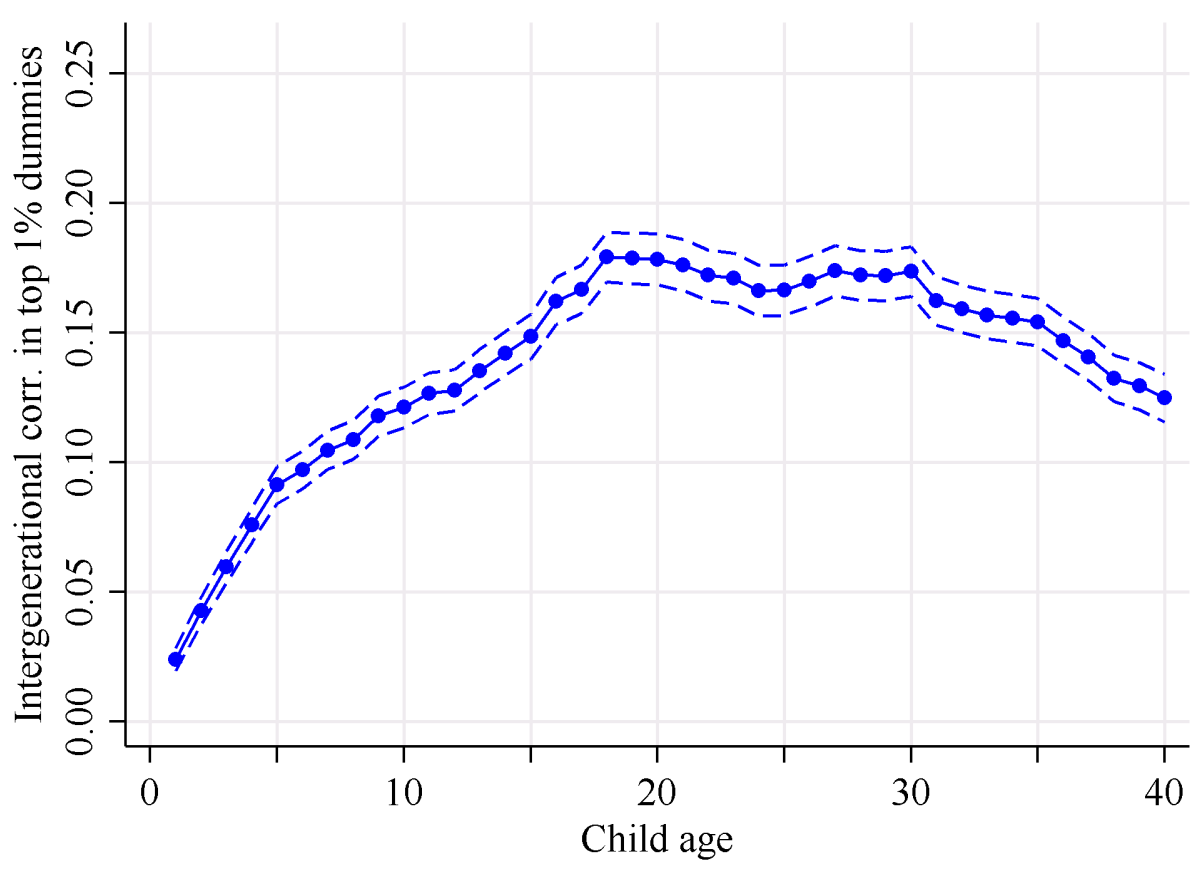

Figure 8: Intergenerational correlation in being in top $1 \%$ by child age

Notes: The figure is based on the PCD sample described in Table A1. It is constructed by first computing the rank of children and parents within child age-year specific wealth distributions and defining the top $1 \%$ dummy accordingly. Parental ranks are measured in the same year as child ranks. We report the coefficients from a regression (separately for each age group of the children) of a child top $1 \%$ dummy on a parent top $1 \%$ dummy and a constant term. The dashed lines represent $95 \%$ confidence bounds using robust standard errors.

\subsection{Does childhood wealth predict adulthood riches?}

In this section, we use the PD sample to explore the relationship between childhood wealth inequality and future wealth inequality in adulthood. Panel A of Figure 9 shows the non-parametric relationship between the children's wealth percentile rank at age 18 and the corresponding position in the wealth distribution nearly three decades later (27 years later to be precise) when the child is 45 years old. Analogously, the figure shows the relationship between parental wealth rank when the child is 18 years old and the children's wealth rank at age 45. Both parental and childhood position in the wealth distribution are strongly correlated with the future position of the child in adulthood, and the rank correlation is actually largest for the children's own position in childhood (with the difference driven primarily by the weak relationship between parental and children's wealth in the lower tail of parental wealth distribution).

probability. For comparison, we have also redone Figure 8 with earnings instead of wealth. The intergenerational correlation of earnings is around zero until the child is 25 years old, and then develops gradually up to its long run level attained around age 30. This is in stark contrast to the intergenerational relationship in wealth, which develops already from the child is born. 
In Appendix E we further show that the correlation coefficient between the wealth position at age 18 and the wealth position later in life stabilizes at a level of $0.2-0.25$ from the time when the child is in the late 20s, that childhood wealth is a strong predictor not just of the average wealth in adulthood, but also of ending up in the very top of the distribution later in life, and finally that childhood wealth at age 1 is also a predictor of the future wealth position later in life.

In panel B of Figure 9, we zoom in on the incremental contribution of childhood wealth rank at 18 over parental rank in explaining wealth in adulthood. To do so, we split the sample into four groups ranked by child's wealth at age 18 (top 10\%, top 10-25\%, top 25-50\% and below the median - selected to maximize transparency). It shows that the groups are systematically ordered: conditional on parental percentile rank, children with higher wealth in childhood have a higher position in the wealth distribution in adulthood. With a few exceptions, the difference between the top $10 \%$ and the bottom $50 \%$ is $10-20$ percentiles in adulthood across all percentiles of parents. This strong effect of childhood wealth conditional on parental wealth is confirmed if we regress child's rank at age 45 on child's rank at age 18 and on parental rank measured at the same time (reported in column 1 of Table 3). In fact, the effect of child's own rank is much larger (0.21) than the effect of parental rank (0.15).

It is difficult to disentangle why childhood wealth is such a strong predictor of wealth in adulthood. One explanation could be that childhood wealth alone is so large that it can accumulate into significant wealth in adulthood. To evaluate this hypothesis, we compute for each eighteen year old individual their potential future wealth at age 45 if their wealth at age 18 accrues over time with a given real rate of return and assuming no spending. ${ }^{16}$ We then derive the share of individuals whose childhood wealth when accumulated in this manner is by itself sufficient to place them above any given percentile of the actual wealth distribution at age 45. Table 2 shows the result for different real rates of return on savings. Take, for example, the real rate of return of 3 percent. At this level, only 2 people out of 10000 , i.e. 0.02 percent, have sufficient wealth at age 18 to make it into the top $1 \%$ group at age 45 by pure wealth accumulation. At a very generous real interest rate of 6 percent, it is still only the 0.1 percent wealthiest at age 18 who can make it into the top $1 \%$ group. Similarly, even the 6 percent rate of return cannot come close to accounting for membership in the broader top wealth groups later in life from childhood wealth alone. Our overall conclusion from Table 2 is that childhood wealth in itself is not a sizable component of future wealth.

\footnotetext{
${ }^{16}$ Their potential future wealth at age 45 is then given by $w_{45}=(1+r)^{45-18} w_{18}$, where $w_{18}$ is their wealth at age 18 , while $r$ is the real rate of return.
} 


\section{A. Partial analysis}

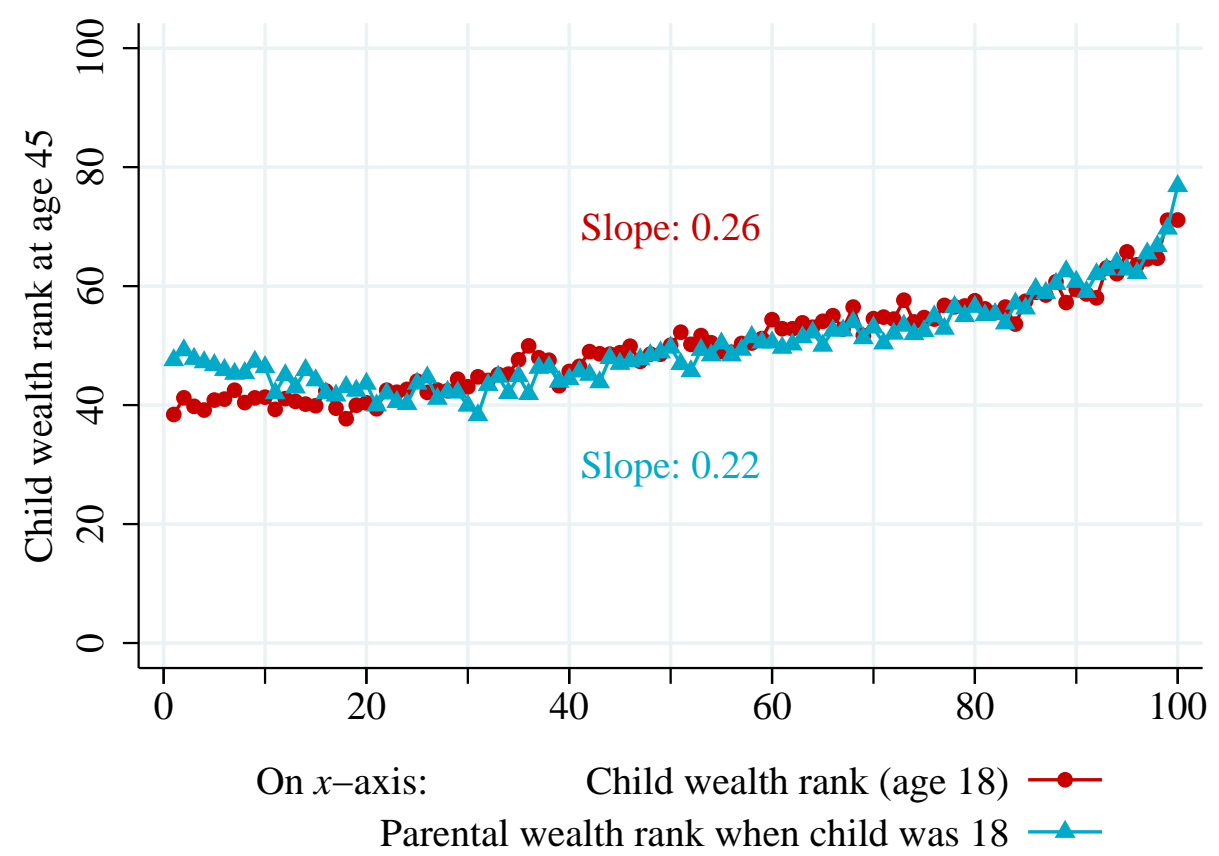

B. Conditional analysis

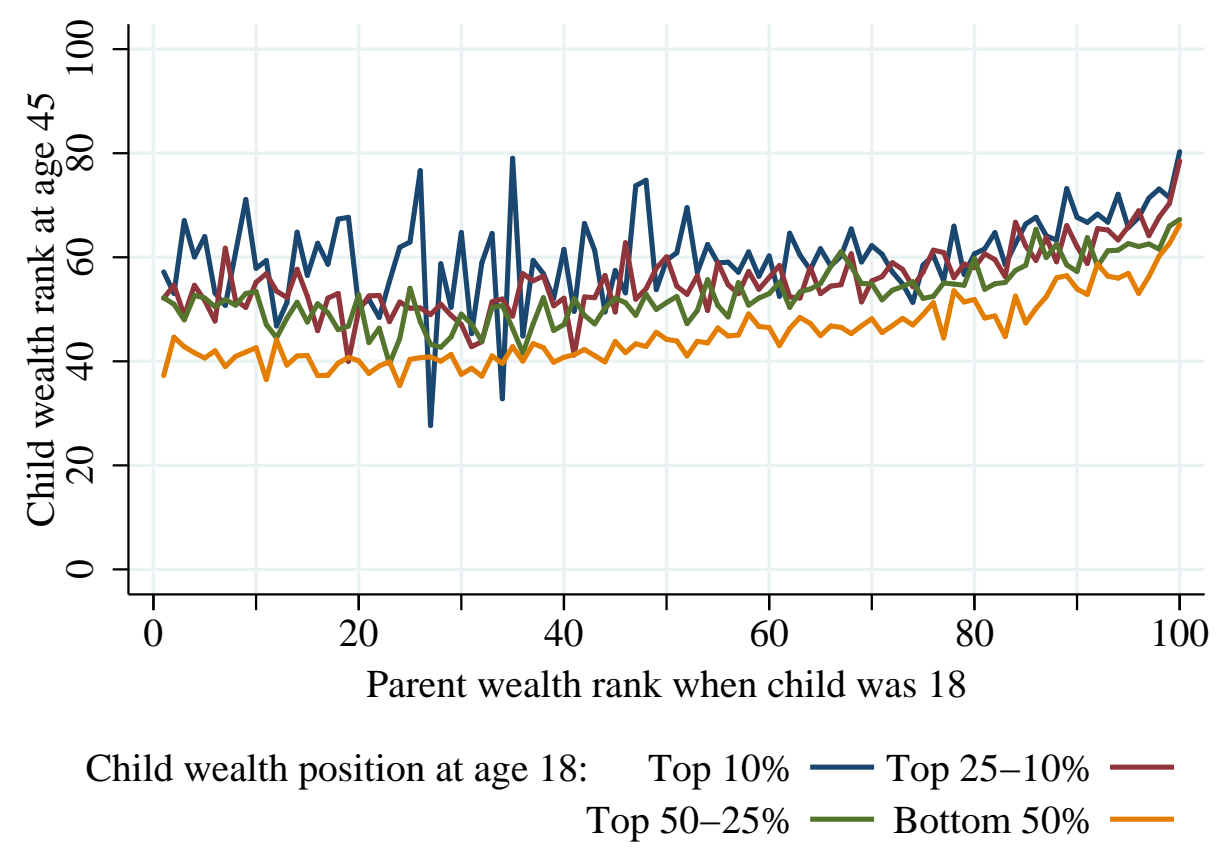

Figure 9: Child's wealth rank at age 45 by parental wealth rank and by own rank at age 18

Notes: The figure relies on the PD sample described in Table A2. Panel A shows the average child wealth rank at age 45, conditional on either parental wealth rank or child's wealth rank (both measured when child was 18). Panel B shows the average child wealth rank at age 45, conditional on parental wealth rank measured when the child was 18 , separately for groups defined based on child's wealth distribution at 18 . All ranks computed within child ageand year-specific wealth distributions. 
Table 2: Share of 18 year olds reaching top wealth groups at age 45

\begin{tabular}{lccc}
\hline \hline \multirow{2}{*}{ Group } & \multicolumn{3}{c}{ Real rate of return } \\
\cline { 2 - 4 } & $0 \%$ & $3 \%$ & $6 \%$ \\
\hline Top 25\% & 0.22 & 0.78 & 3.41 \\
Top 10\% & 0.08 & 0.22 & 0.76 \\
Top 5\% & 0.03 & 0.12 & 0.38 \\
Top 1\% & 0.00 & 0.02 & 0.10 \\
\hline \hline
\end{tabular}

Notes: Calculated using the PD sample described in Table A2. The table is constructed by computing, for each eighteen year old individual, their potential future wealth at age 45 if their wealth at age 18 had accrued over time with a given real rate of return and assuming no spending. The table reports the share of individuals whose childhood wealth, accumulated in this manner, would by itself be sufficient to place them above a given percentile of the actual wealth distribution at age 45 .

In order to shed more light on the mechanisms behind the strong predictive power of childhood wealth, we pursue a strategy analogous to the approach of Charles and Hurst (2003) and run regressions of child's rank at age 45 where we -in addition to child's rank at age 18 and parental rank measured at the same time - include earnings, education, and portfolio composition of both parents and children as regressors. If inclusion of these characteristics significantly dampens the coefficient of child's rank at age 18 then it implies that these additional variables are strongly related to wealth in adulthood and also strongly correlated with childhood wealth. Hence, the mechanisms underlying the predictive power of childhood wealth may run through these variables. For example, many studies have highlighted the importance of family conditions and formation of human capital during childhood (e.g. Cunha and Heckman 2007 and Carneiro, Garcia, Salvanes, and Tominey 2015). It could be that parents who give to their children financially also make important investments in human capital during childhood, which make the children wealthy later in life. In this explanation, childhood wealth is a proxy for important parental human capital investments. Wealth obtained during childhood may also in itself promote future education, if credit constraints are important, and thereby lead to higher earnings and wealth in adulthood.

Column 2 of Table 3 reports the result when earnings are included in the regression. It shows that conditional on wealth, the earnings levels of child and parents when the child is 18 have negligible explanatory power, but that child's own earnings at age 45 has a large positive coefficient. Note, however, that the coefficient on childhood wealth is only slightly smaller than the coefficient in column 1. Hence, although earnings in adulthood are important, it does not seem to be the 
Table 3: Rank-rank regressions of child wealth rank at age 45 on child and parental wealth ranks measured when the child was 18 years old.

\begin{tabular}{lcccccc}
\hline \hline & $(1)$ & $(2)$ & $(3)$ & $(4)$ & $(5)$ & $(6)$ \\
\hline Child wealth rank (age 18) & 0.213 & 0.202 & 0.185 & 0.163 & 0.087 & 0.086 \\
& $(0.005)$ & $(0.005)$ & $(0.006)$ & $(0.006)$ & $(0.005)$ & $(0.005)$ \\
Parental wealth rank (when child was 18) & 0.151 & 0.143 & 0.134 & 0.114 & 0.073 & 0.070 \\
& $(0.005)$ & $(0.005)$ & $(0.005)$ & $(0.006)$ & $(0.005)$ & $(0.005)$ \\
Child earnings rank (age 18) & & -0.030 & -0.016 & & & -0.011 \\
& & $(0.005)$ & $(0.005)$ & & & $(0.005)$ \\
Parental earnings rank (when child was 18) & & -0.022 & -0.038 & & & -0.002 \\
& & $(0.005)$ & $(0.006)$ & & & $(0.006)$ \\
Child earnings rank (age 45) & & 0.125 & 0.092 & & & 0.013 \\
& & $(0.005)$ & $(0.006)$ & & & $(0.006)$ \\
Education dummies & & & $\mathrm{X}$ & & & $\mathrm{X}$ \\
Portfolio variables (when child was 18) & & & & $\mathrm{X}$ & $\mathrm{X}$ & $\mathrm{X}$ \\
Child portfolio variables (when child is 45) & & & & & $\mathrm{X}$ & $\mathrm{X}$ \\
Constant & & & & & 44.328 & 44.145 \\
& 31.794 & 29.107 & 27.078 & 40.367 & & \\
& $(0.334)$ & $(0.503)$ & $(0.767)$ & $(0.620)$ & $(0.562)$ & $(0.807)$ \\
\hline Observations & 36,102 & 36,102 & 36,102 & 36,102 & 36,102 & 36,102 \\
R-sq. & 0.087 & 0.104 & 0.113 & 0.112 & 0.339 & 0.342 \\
Adj. R-sq. & 0.087 & 0.103 & 0.112 & 0.112 & 0.339 & 0.341 \\
\hline \hline
\end{tabular}

Notes: Analysis based on the PD sample described in Table A2. Results from OLS regressions, the dependent variable is wealth rank at 45. All ranks are calculated within child age cohort and year. Robust standard errors in parentheses.

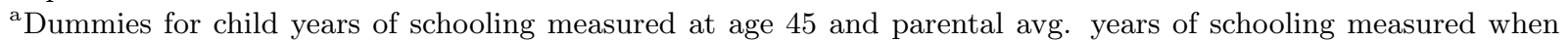
child was 18. ${ }^{\mathrm{b}}$ Dummy variables for child and parental stock ownership when child was 19, child and parental homeownership when child was 22 , child and parental debt holding when child was 22, and child and parental self-employment status when child was $18 .{ }^{\mathrm{c}}$ Dummy variables for stock ownership, homeownership, debt-holdings, and self-employment status at age 45 .

case that childhood wealth is a strong predictor of future wealth only because it proxies for future earnings opportunities of the child. The coefficient on childhood wealth falls a little more when we in addition to earnings include years of schooling dummy variables for both parents and children (measured when the child is 45 years old) in column 3, but a very large part is still unexplained. This indicates that the channels underlying the predictive power of childhood wealth do not simply operate through labor market outcomes.

In columns 4 and 5, we incorporate portfolio variables -indicators for stock ownership, homeownership, self-employment, and any debt - that may proxy for differences across people in financial behavior. This may capture that the existence of childhood wealth coincides with certain investment styles/preferences for wealth accumulation that are transmitted across generations. We first consider portfolio variables measured when the child was 18-both for parents and the child (col- 
umn 4). Their inclusion reduces the coefficient on child wealth more than the inclusion of earnings and education, which may indicate that financial behavior has some role to play in explaining the predictive power of childhood wealth. In column 5, we include the child's portfolio characteristics at age 45, which has a very large dampening effect on the childhood wealth coefficient. This may indicate a strong role of financial behavior, but of course as in the analysis of Charles and Hurst (2003) it may also simply reflect reverse causality of wealth on portfolio choices. To conclude, the reasonably strong effects of simple portfolio indicators might suggest that important mechanisms underlying the predictive power of childhood wealth operate through savings and investment behavior.

In column 6, we include all control variables, which significantly reduces the coefficient on childhood wealth, but still leaves a large share unexplained.

Another possible explanation for why childhood wealth predicts future wealth, while not in itself being large enough to accumulate into future wealth, is that those receiving transfers in childhood continue to receive transfers in adulthood. It is difficult to test this hypothesis as we do not observe transfers directly. However, as an indirect test we analyze whether childhood wealth, conditional on parental wealth, predicts 'potential bequests' received in the future. We do this by considering a small sample of children from the 1965 birth cohort where both parents die during the period from when the child is age 18 to 46 (reflecting as described previously that you normally in Denmark do not receive any bequests before both parents have died). We then compute 'potential bequests' as the wealth of the last living parent before death divided by the number of children, and then rank the potential bequests according to size within the year of death. Note that this approach controls for correlation between wealth and longevity, and that our rank measure reflects the position of the individual in the true distribution of bequests as long as there exists a monotone relationship between actual bequests and our measure of potential bequests. Table 4 reports the results from regressing our measure of future expected bequests on childhood wealth and parental wealth. Both wealth measures are strongly related to potential bequests as might be expected, but, more interestingly, childhood wealth is strongly correlated with future expected bequests, conditional on parental wealth. Children who are ten deciles higher in the wealth distribution at age 18 will on average be two percentiles higher in the expected bequests distribution.

Together with the previous analysis on the origins of childhood wealth, this analysis indicates that children who receive transfers during childhood continue to do so later in life. In Appendix F, we repeat the analysis in Table 3 using this small sample and include potential bequests among 
Table 4: Rank-rank regressions with potential bequests as dependent variable

\begin{tabular}{lccc}
\hline \hline & $(1)$ & $(2)$ & $(3)$ \\
\hline Child wealth rank at age 18 & 0.339 & & 0.202 \\
& $(0.013)$ & & $(0.012)$ \\
Parental wealth rank when child was age 18 & & 0.496 & 0.431 \\
& & $(0.012)$ & $(0.013)$ \\
Constant & & & \\
& 33.038 & 25.212 & 18.343 \\
Observations & $(0.737)$ & $(0.738)$ & $(0.784)$ \\
R-sq. & 5,469 & 5,469 & 5,469 \\
Adj. R-sq. & 0.115 & 0.246 & 0.282 \\
\hline \hline
\end{tabular}

Notes: Regressions in this table are based on the group of children in the 1965 age cohort who lose their last living parent. Potential bequests are calculated as wealth of that parent the year prior to dying, divided by the number of children of that parent in the year of death. Potential bequests are ranked among potential bequests in the same year of death. In order that rankings make sense, we only use a year of death if there are at least 100 observed deaths. Thus, we use years from 1997-2011, where children are aged 32-46. Child and parental wealth ranks when children were aged 18 are ranked within that year. Robust standard errors in parentheses.

the regressors. This shows that potential bequests are strongly correlated with child wealth in adulthood, also when including all the previous controls, and indicates that this proxy for future transfers may have a role to play in explaining why childhood wealth predicts wealth in adulthood.

\section{Concluding remarks}

Understanding wealth inequality and its development across generations is a subject of active research. Using Danish data, we show that the intergenerational wealth relationship develops through childhood and teenage years. In particular, we find that wealth of the child when entering into adulthood is even more informative than wealth of parents in predicting future economic wellbeing. We show that the role of childhood wealth is not primarily due to its direct impact on future wealth through accumulation (because they are too small), but rather they are a marker for characteristics that are not captured by parental wealth alone. By itself, it highlights important heterogeneity among people with otherwise similar wealth - those who give to their children end up with children who are wealthier in adulthood (holding parental wealth constant). We show that this relationship is not explained simply by interaction of childhood wealth with future earnings or education that are well-known to be correlated across generations. Rather childhood wealth seems to be a proxy for a broader set of circumstances that impact future wealth accumulation. 
In particular, our evidence suggests that it may be related to an intergenerational correlation in savings/investment behavior and that children receiving transfers in childhood continue to do so in adulthood.

These results indicate that understanding direct inter vivos transfers and transmission of financial behavior is important for understanding intergenerational wealth mobility. Hence, our results complement findings in Björklund, Roine, and Waldenström (2012) and Boserup, Kopczuk, and Kreiner (2015) - who document that wealth persistence at the top of the distribution is much stronger than for the general population - by indicating that different mechanisms are at play in making these relationships unfold and that they unfold at different points in childhood. These findings also indicate that we may gain insights about wealth concentration in the future by observing current children's wealth holdings. This is particularly interesting given the recent focus on top wealth (Piketty 2014) that puts particular emphasis on issues surrounding intergenerational wealth mobility and difficulties in measuring contemporaneous trends in wealth concentration (see Bricker et al. 2014, Saez and Zucman 2016, and Kopczuk 2015). 


\section{References}

[1] Adermon, Adrian, Mikael Lindahl and and Daniel Waldenström (2015). "Intergenerational wealth mobility and the role of inheritance: Evidence from multiple generations." Working paper.

[2] Arrondel, Luc and André Masson (2006). "Altruism, exchange or indirect reciprocity: what do the data on family transfers show?," in Serge-Christophe Kolm and Jean Mercier Ythier, eds., Handbook on the Economics of Giving, Reciprocity and Altruism, Vol. 2, Elsevier, chapter 14, 971-1053.

[3] Bernheim, B. Douglas, Robert J. Lemke, and John Karl Scholz (2004). "Do Estate and Gift Taxes Affect the Timing of Private Transfers?" Journal of Public Economics 88(12), $2617-34$.

[4] Black, Sandra and Paul J. Devereux (2011). "Recent Developments in Intergenerational Mobility." In: Ashenfelter, O. and D. Card (Eds.), Handbook of Labor Economics. Vol. IVb. North-Holland, Amsterdam, 1487-1541.

[5] Black, Sandra, Paul J. Devereux and Kjell Salvanes (2007). "From the cradle to the labor market? The effect of birth weight on adult outcomes." Quarterly Journal of Economics 122(1), 409-439.

[6] Black, Sandra, Paul J. Devereux, Petter Lundborg, and Kaveh Majlesi (2015). "Poor Little Rich Kids? The Determinants of the Intergenerational Transmission of Wealth." NBER Working Paper No. 21409.

[7] Björklund, Anders, Jesper Roine, and Daniel Waldenström (2012). "Intergenerational top income mobility in Sweden: Capitalist dynasties in the land of equal opportunity?" Journal of Public Economics 96, 474-484.

[8] Boserup, Simon Halphen, Wojciech Kopczuk, and Claus Thustrup Kreiner (2015). "Intergenerational Wealth Mobility: Evidence from Danish Wealth Records of Three Generations." Working paper.

[9] Boserup, Simon Halphen, Wojciech Kopczuk, and Claus Thustrup Kreiner (2016). "The Role of Bequests in Shaping Wealth Inequality: Evidence from Danish Wealth Records." American Economic Review Papers and Proceedings 106(5), 656-661.

[10] Bricker, Jesse, Lisa J. Dettling, Alice Henriques, Joanne W. Hsu, Kevin B. Moore, John Sabelhaus, Jeffrey Thompson, and Richard A. Windle (2014). "Changes in U.S. 
Family Finances from 2010 to 2013: Evidence from the Survey of Consumer Finances." Federal Reserve Bulletin, 100(4), 1-40.

[11] Carneiro, Pedro, Italo L. Garcia, Kjell G. Salvanes, and Emma Tominey (2015). "Intergenerational Mobility and the Timing of Parental Income." Working paper.

[12] Charles, Kerwin K. and Erik Hurst (2003). "The Correlation of Wealth across Generations." Journal of Political Economy 111, 1155-1182.

[13] Chetty, Raj (2012). "Bounds on Elasticities with Optimization Frictions: A Synthesis of Micro and Macro Evidence on Labor Supply." Econometrica 80(3), 969-1018.

[14] Chetty, Raj, Nathan Hendren, Patrick Kline, and Emmanuel Saez (2014). "Where is the Land of Opportunity? The Geography of Intergenerational Mobility in the United States." Quarterly Journal of Economics 129(4), 1553-1623.

[15] Clark, Gregory and Neil Cummins (2014). "Intergenerational Wealth Mobility in England, 1858-2012. Surnames and Social Mobility." Economic Journal 125, 61-85.

[16] Cunha, Flavio and James Heckman (2007). "The Technology of Skill Formation." American Economic Review 97, 31-47.

[17] Elinder, Mikael, Oscar Erixson and Daniel Waldenström (2016). "Inheritance and Wealth Inequality: Evidence from Population Registers." CEPR Discussion Paper 11191.

[18] Fagereng, Andreas, Magne Mogstad and Marte Rønning (2015). "Why do wealthy parents have wealthy children." Statistics Norway Discussion Paper.

[19] Joulfaian, David (2005). "Choosing between gifts and bequests: How taxes affect the timing of wealth transfers." Journal of Public Economics 89(11-12), 2069-2091.

[20] Kleven, Henrik J., Martin B. Knudsen, Claus T. Kreiner, Søren Pedersen, and Emmanuel Saez (2011). "Unwilling or Unable to Cheat? Evidence from a Tax Audit Experiment in Denmark." Econometrica 79, 651-692.

[21] Kopczuk, Wojciech (2007). "Bequest and Tax Planning: Evidence from Estate Tax Returns." Quarterly Journal of Economics 122(4), 1801-1854.

[22] Kopczuk, Wojciech (2013), "Taxation of Intergenerational Transfers and Wealth," in Alan J. Auerbach, Raj Chetty, Martin S. Feldstein, and Emmanuel Saez, eds., Handbook of Public Economics, Vol. 5, Elsevier, 329-90.

[23] Kopczuk, Wojciech (2015), "What Do We Know About the Evolution of Top Wealth Shares in the United States?" Journal of Economic Perspectives, 29(1), 47-66. 
[24] Laferrère, Anne and François-Charles Wolff (2006), "Microeconomic models of family transfers," in Serge-Christophe Kolm and Jean Mercier Ythier, eds., Handbook on the Economics of Giving, Reciprocity and Altruism, Vol. 2, Elsevier, chapter 13, 889-969.

[25] Laitner, John (1997), "Intergenerational and Interhousehold Economic Links," in Mark K. Rosenzweig and Oded Stark, eds., Handbook of Population and Family Economics, Vol. 1A, Amsterdam; New York: Elsevier/North Holland.

[26] Leth-Petersen, Søren (2010). "Intertemporal Consumption and Credit Constraints: Does Total Expenditure Respond to An Exogenous Shock to Credit?" American Economic Review 100(3), 1080-1103.

[27] Motteux, Peter Anthony (1719). "The History of the Renowned Don Quixote de la Mancha." Vol. 4. London: Printed for Sam. Buckley, 1700-1712.

[28] Piketty, Thomas (2014). "Capital in the Twenty-First Century." Harvard University Press.

[29] Saez, Emmanuel (2010). "Do Taxpayers Bunch at Kink Points?" American Economic Journal: Economic Policy 2, 180-212.

[30] Saez, Emmanuel and Gabriel Zucman (2016), "Wealth Inequality in the United States since 1913: Evidence from Capitalized Income Tax Data." Quarterly Journal of Economics 131(2), 519-578.

[31] Solon, Gary (1999). "Intergenerational mobility in the labor market." In: Ashenfelter, O. and D. Card (Eds.), Handbook of Labor Economics. Vol III. North-Holland, Amsterdam, 17611800.

[32] Solon, Gary (2015). "What Do We Know So Far about Multigenerational Mobility?" NBER Working Paper No. 21053. 


\section{A Summary statistics}

Table A1 provides summary statistics of the variables in the PCD sample for 10-year age intervals. It shows that average wealth is low for children of age 1-10 and nearly 100 times as high for the age group 31-40. Wealth is a little lower for the age group 21-30 than the age group 11-20, reflecting liabilities (including study loans) and possibly also pension savings not registered in the data. The sample contains on average close to 650 thousand observations in each one-year age group of the children. Variation in the number of observations across child age in the sample reflects that older children are more likely to have lost one of their parents and that the size of the cohorts varies with, e.g., large cohorts in the age group 31-40 compared to the age group 21-30.

Table A2 provides summary statistics of the variables in the PD sample. Apart from wealth, the table also provides information of education, earnings, and portfolio variables. 
Table A1: Summary statistics - Pooled cross-section data (PCD) sample

\begin{tabular}{lcccc}
\hline \hline & \multicolumn{4}{c}{ Child age } \\
\cline { 2 - 5 } DKK, 2011-prices & $1-10$ & $11-20$ & $21-30$ & $31-40$ \\
\hline Bank deposits & 617 & 14,501 & 40,095 & 71,313 \\
Securities & $(23,623)$ & $(83,441)$ & $(195,270)$ & $(446,956)$ \\
& 1,771 & 7,604 & 14,370 & 27,810 \\
Real estate & $(127,084)$ & $(632,796)$ & $(1,055,028)$ & $(1,968,994)$ \\
& 16 & 2,236 & 264,965 & 863,205 \\
Other assets & $(13,126)$ & $(130,400)$ & $(2,197,072)$ & $(5,451,549)$ \\
& 2 & 20 & 658 & 2,570 \\
Total assets & $(2,542)$ & $(13,144)$ & $(686,637)$ & $(413,558)$ \\
& 2,407 & 24,361 & 320,088 & 964,897 \\
Total liabilities & $(137,155)$ & $(676,875)$ & $(2,717,950)$ & $(6,098,993)$ \\
& 1 & 4,833 & 305,509 & 750,996 \\
Net wealth & $(843)$ & $(71,665)$ & $(1,670,940)$ & $(4,247,502)$ \\
& 2,406 & 19,527 & 14,579 & 213,901 \\
Mean earnings & $(137,145)$ & $(669,179)$ & $(1,956,860)$ & $(3,709,353)$ \\
& 12 & 25,453 & 189,335 & 304,764 \\
Parental net wealth & $(684)$ & $(72,770)$ & $(300,709)$ & $(503,533)$ \\
& 610,645 & $1,036,748$ & $1,477,664$ & $1,874,573$ \\
Share of children & $(8,341,717)$ & $(14,595,772)$ & $(15,063,383)$ & $(14,616,828)$ \\
with all grandparents alive & 0.4602 & 0.1981 & 0.0271 & 0.0004 \\
\hline Observations & $7,135,138$ & $6,687,894$ & $6,050,215$ & $6,051,702$ \\
\hline \hline
\end{tabular}

Notes: Pooled information for the years 2000-2011. The PCD sample contains for each year all Danes in the age group 1-40 years, where both parents are alive. The table reports mean values and standard deviations (in parentheses) of the variables. Standard deviations are clustered at the individual child level. The category Bank deposits includes all types of deposit accounts in banks and other financial intermediaries. The category Securities includes all publicly traded stocks, bonds, derivatives, etc. Real estate denotes the public value of real estate assessed by the Danish tax agency. Following Leth-Petersen (2010), public values are adjusted in each year using the average relative difference between the selling price and the public value of houses sold in that year in order to account for that public values underestimate the market values. Spouses with joint ownership of assets are each registered with half of the total asset value. The component Other assets is computed as the residual after subtracting deposits, securities, and real estate from total assets in the registers and reflects for example company values of self-employed. The category Total assets denotes the aggregate value of assets in the registers adjusted for the underestimation of real estate values. The category Total liabilities is the aggregate value of liabilities in the registers and includes all types of interest-bearing debt. Net wealth is defined as total assets minus total liabilities. Parental net wealth is the sum of net wealth of the biological father and mother. All values are converted to 2011 DKK prices using the GDP deflator (exchange rates are approximately equal to 8.5 DKK per GBP, 7.5 DKK per EURO, and 5.5 DKK per USD in 2011). 
Table A2: Summary statistics-Panel data (PD) sample

\begin{tabular}{lccc}
\hline \hline & \multicolumn{3}{c}{1965 child cohort } \\
\cline { 2 - 4 } Mean (SD) & $\begin{array}{c}\text { Children } \\
\text { at age } 18\end{array}$ & $\begin{array}{c}\text { Children } \\
\text { at age } 45\end{array}$ & $\begin{array}{c}\text { Parents when } \\
\text { child was } 18\end{array}$ \\
\hline Wealth (DKK, 2011-prices) & 30,963 & 358,096 & 504,367 \\
Earnings (DKK, 2011-prices) & $(122,182)$ & $(2,036,086)$ & $(2,194,585)$ \\
Years of schooling & 87,770 & 349,113 & 659,804 \\
Share of children with/whose parents have: & $(82,285)$ & $(288,842)$ & $(416,209)$ \\
Stocks & & 14.09 & 10.42 \\
Real estate & 0.04 & $(2.23)$ & $(2.74)$ \\
Debt & $(0.19)$ & $(0.44)$ & $(0.34)$ \\
Self-employment status & 0.17 & 0.68 & 0.83 \\
& $(0.38)$ & $(0.47)$ & $(0.37)$ \\
Observations & 0.64 & 0.80 & 0.78 \\
\hline \hline
\end{tabular}

Notes: Balanced panel data covering the years 1983-2011 for the age cohort of 1965 . Wealth and earnings are deflated using nominal GDP. Variables are measured at the ages indicated with the following exceptions for measurement at "child age 18": stock ownership at age 19; real estate ownership and debtholding at age 22 . 


\section{B Stability of pooled cross-section results}

In Figures B1 and B2, we replicate Figures 1 and 3 for each of the 12 years in the sample, thereby showing the cross-sectional age variation in each year 2000-2011 instead of pooling the data. The graphs reveal some variation over time (for example, for older adults in the sample wealth increases before the financial crisis and then decreases sharply afterwards), but during childhood the differences are small compared to the differences across age and between the different percentiles in the age-specific distribution. Note also that we in the empirical analysis control for time and cohort effects by defining percentile ranks and top $1 \%$ indicators within cohort-year.

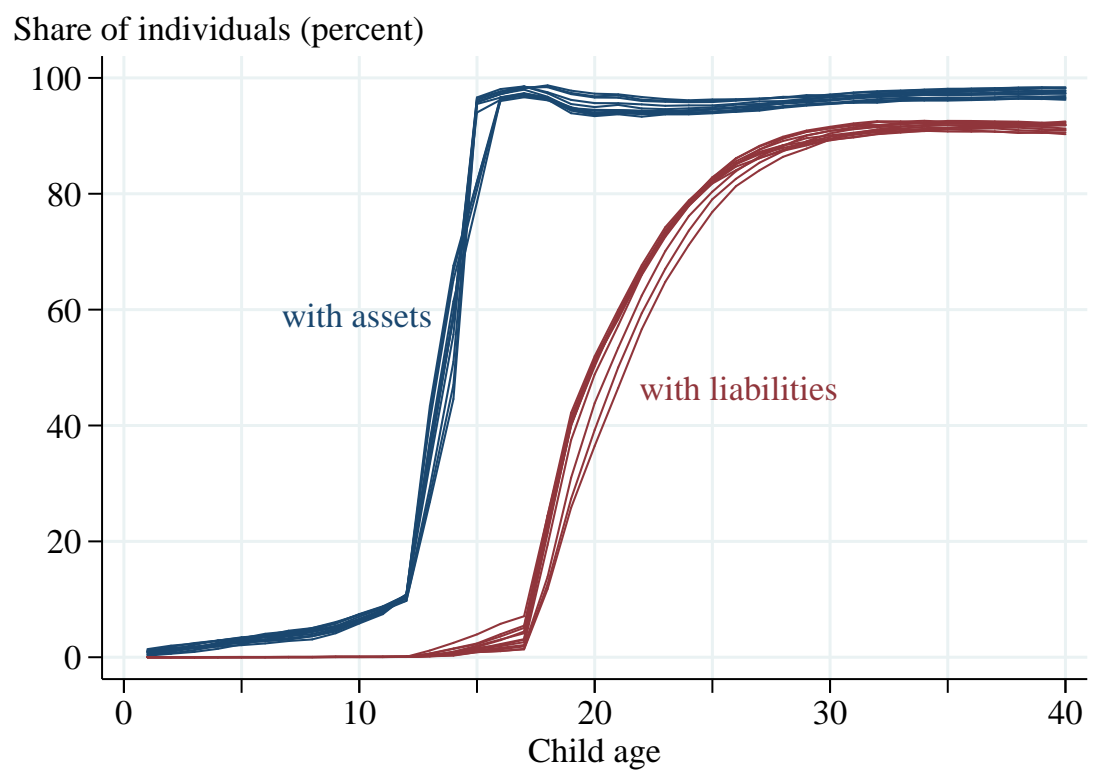

Figure B1: Share of individuals owning assets (percent) by age for each year 2000-2011

Notes: The figure shows a variation of Figure 1. The figure shows the cross-sectional age variation in each year 2000-2011 represented by one curve per year. 


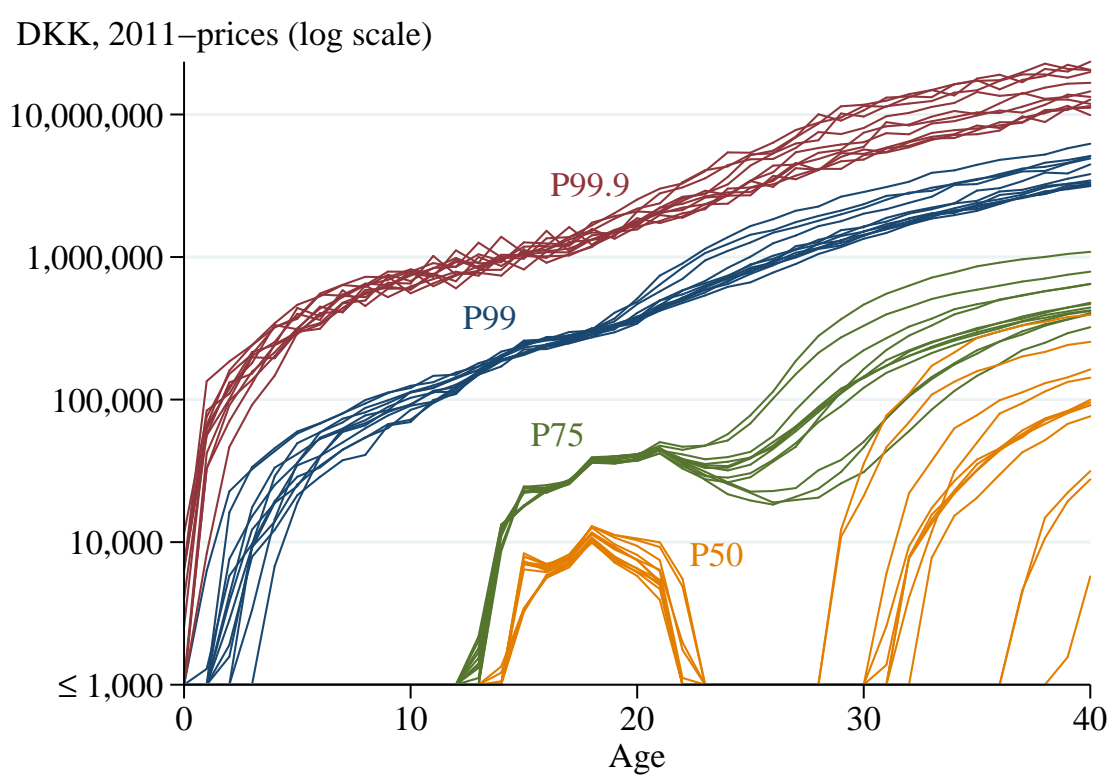

Figure B2: Top wealth percentiles, DKK-2011-prices (log scale) by age for each year 2000-2011 Notes: The figure shows a variation of Figure 3. The figure shows the cross-sectional age variation in each year 2000-2011 represented by one curve per year. 


\section{Effect of bequests received from grandparents}

Figure C1 provides a few sensitivity analyses concerning the potential impact of bequests from grandparents. In Figure 5, we only look at the share of individuals with positive net-wealth. In Figure C1, panel A, we zoom in on wealthy children by displaying the average wealth of the top $1 \%$ group overall and show the same graph for a restricted sample of the top $1 \%$ group among those with all four grandparents are alive. The graphs are nearly identical, indicating that bequests from grandparents are not the driving force behind the wealth of wealthy children. Unfortunately, we do not have sufficient statistical power to supplement this descriptive evidence with an event analysis. In panel B, we conduct an event analysis similar to panel B of Figure 5, but this time with a top $1 \%$ dummy as outcome variable. The graph indicates that there may be an effect on the propensity to be in the top $1 \%$ group, but the change in the propensity is small and insignificant. In panel C, we redo the event analysis in panel B of Figure 5, but this time with 2005 as the event year (in order to test sensitivity to year choice and the longer follow-up period). Again, the graphs of the treatment and control groups are very close to each other both before and after grandparental death, indicating that bequests from grandparents are not the driving force behind the wealth

of children. Graphs using 2006 and 2008 as event years (available upon request) are practically identical to those with 2005 and 2007 as event years. 


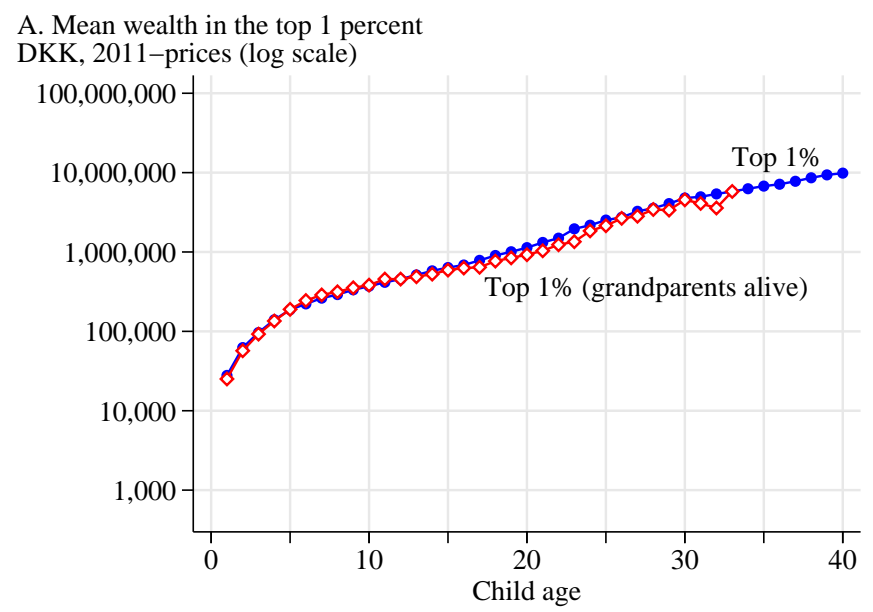

B. Share of individuals (\%) in wealth top 1 percent

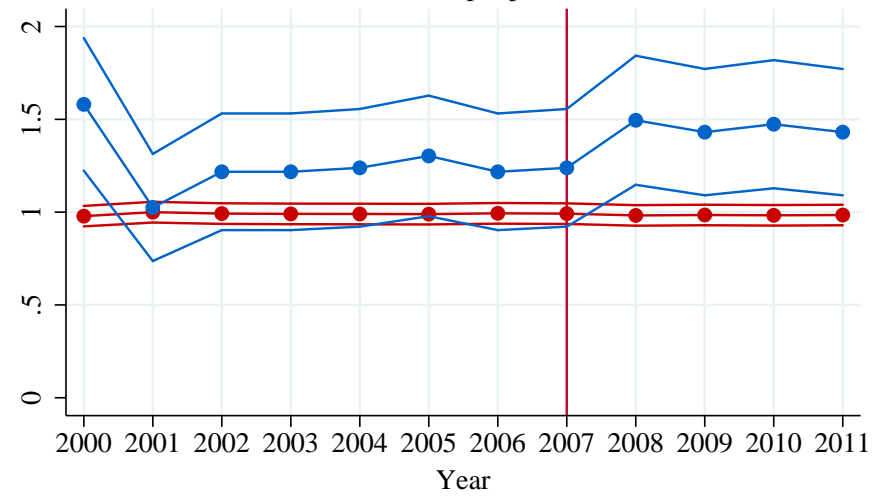

- Control Treatment

C. Share of individuals $(\%)$ with wealth $>100 \mathrm{DKK}$

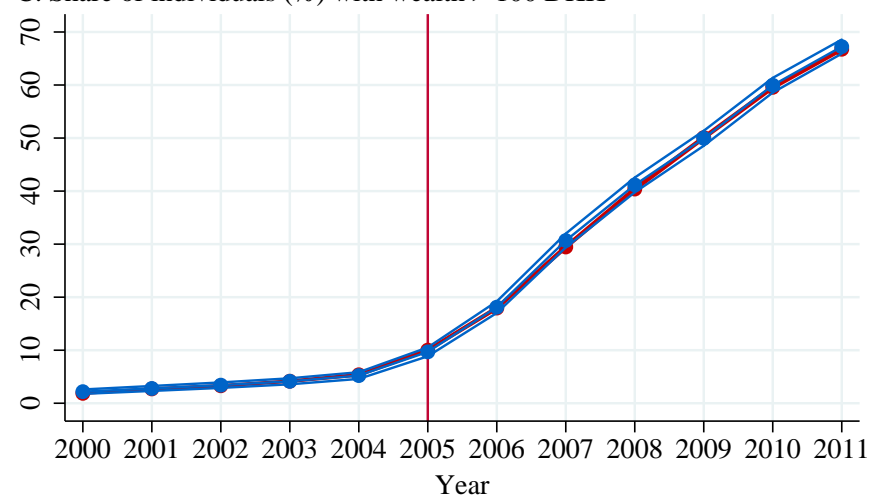

- Control $\longrightarrow$ Treatment

Figure C1: The effect of grandparental death on wealth

Notes: The figures are based on the PCD sample described in Table 1. Panel A compares wealth of the top $1 \%$ in the full sample with wealth of the top $1 \%$ among those with all grandparents alive. Panel B, shows the event study analogous to panel B of Figure 5, using instead top 1\% status as the outcome. Panel C replicates panel B of Figure 5 with 2005 as the event year. 


\section{A simple theory of bunching in wealth transfers}

This appendix shows in a simple theoretical setting the standard argument for why we should expect bunching in the distribution of transfers when transfers below a basic allowance are untaxed, whereas transfers above the threshold are taxed at a non-trivial marginal tax rate. We consider a simple model of giving-behavior, where individual preferences and budget constraint are given by

$$
\begin{aligned}
u & =\alpha \ln c+\beta \ln q+(1-\alpha-\beta) \ln s, \\
w & \leq c+q+T(q)+s,
\end{aligned}
$$

where $w$ is resources of the individual at a given point in time, $c$ is consumption, $s$ is savings for future periods, and $q$ is transfers to offspring taxed according to the tax scheme $T(q)$. Finally, $\alpha$ and $\beta$ are parameters. The tax payment is zero for $q \leq \bar{q}$ and equal to $t(q-\bar{q})$ for $q>\bar{q}$, where $\bar{q}$ is the basic allowance. Maximizing the utility function with respect to the budget constraint gives the following optimal level of transfers:

$$
q=\left\{\begin{array}{cc}
\beta w & w<\bar{q} / \beta \\
\bar{q} & \bar{q} / \beta \leq w \leq[1+t(1-\beta)] \bar{q} / \beta \\
\beta \frac{w+t \bar{q}}{1+t} & w>[1+t(1-\beta)] \bar{q} / \beta
\end{array}\right.
$$

This expression shows that differences across individuals in resources $w$ generate different levels of transfers with a spike in the distribution at $\bar{q}$ where individuals with intermediate levels of resources bunch together due to the discrete change in the marginal tax rate.

Different preferences - variation in the giving-motive parameter $\beta$-is another possible source of variation in transfer levels across individuals, and also in this case there will be bunching at the threshold $\bar{q}$. To see this, consider the case where all individuals have the same level of resources $w$. From eq. (1), it then follows that individuals with a giving motive $\beta$ in the range $\left[\frac{\bar{q}}{w}, \frac{(1+t) \bar{q}}{w+t \bar{q}}\right]$ will bunch together at $\bar{q}$. Thus, independently of whether differences in transfers across individuals are governed by variation in resources or in preferences, we should expect to observe bunching at the threshold where transfers become taxable if tax incentives are important. 


\section{E The role of childhood wealth in predicting future wealth over the life cycle}

The important role of childhood wealth in predicting future outcomes can also be shown by tracing the persistence of wealth ranks over time. In Figure E1, we show the correlation of the rank of wealth at age 18 with the rank of wealth at later ages. While it naturally declines with age, it stabilizes around 0.2 by age of 25 and stays there until people are in their $40 \mathrm{~s}$.

In Figure E2, we show analogous analyses using the top 1\% dummy. Panel A looks at individuals born as wealthy babies - defined as individuals who were one year old in 1983 and among the top $1 \%$ wealthiest within the cohort at that time. When these individuals are five years old, $44 \%$ are still among the top $1 \%$ wealthiest within the cohort of peers who were also present in 1983. More interestingly, the curve converges to a level of about 5 percent, which is significantly larger than the random odds of 1 percent. Hence, despite the small size of wealth holdings at age 1, early-life wealth holdings convey a signal of future position in the wealth distribution. In panel B, we follow instead the cohort who was 18 years old in 1983 and 46 years old at the end of the period. The top $1 \%$ group converges in this case to 15 percent. Thus, high wealth in early adulthood is a very strong indicator of having high wealth more than 25 years later despite the fact that the mean wealth in top $1 \%$ at age 18 is only $1 / 10$ th of what it is at age 40.

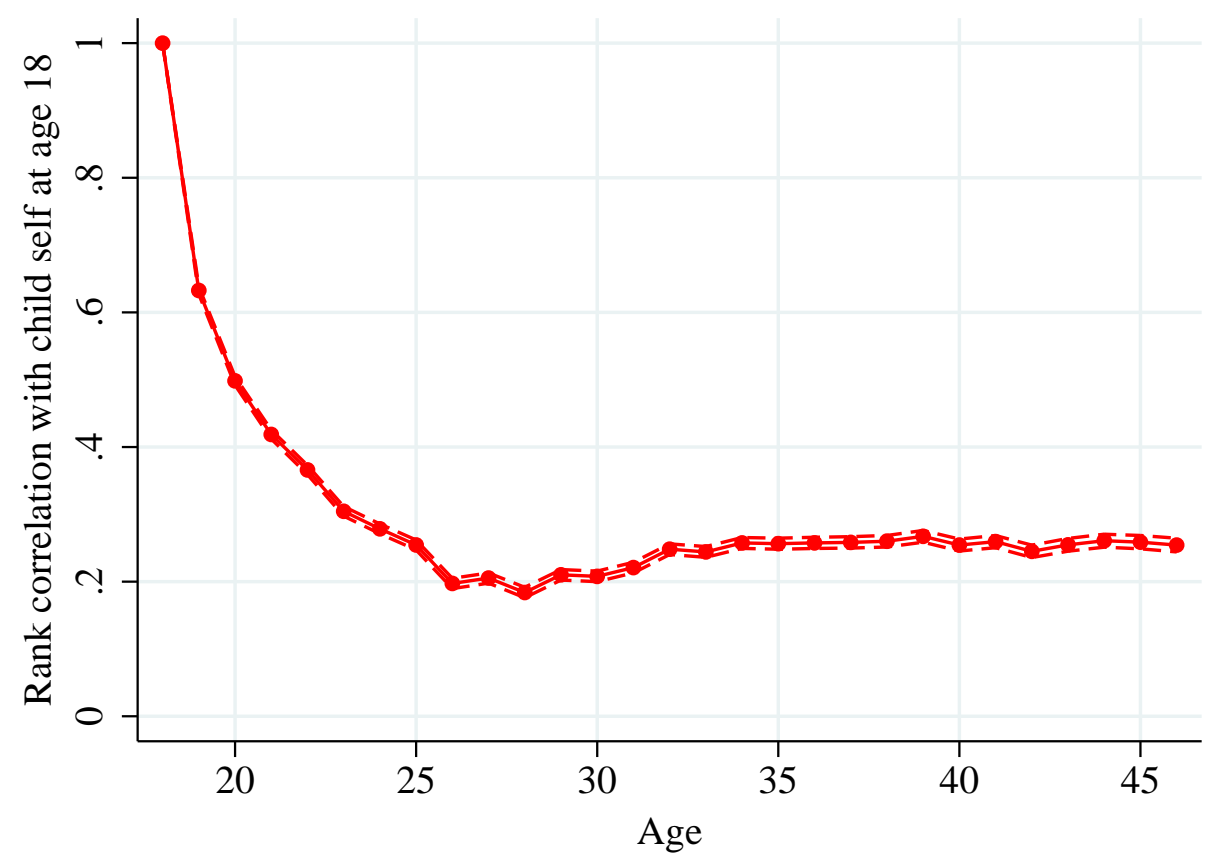

Figure E1: Wealth rank correlations with own wealth rank at age 18

Notes: The figure relies on the PD sample described in Table A2. It shows the correlation of child's rank at a given age with child's wealth rank at 18. All ranks computed within given group's age- and year-specific wealth distributions. Dashed lines are 95\% confidence bands calculated using robust standard errors. 
A. Age 1 in 1983

Share in top $1 \%$ (percent)

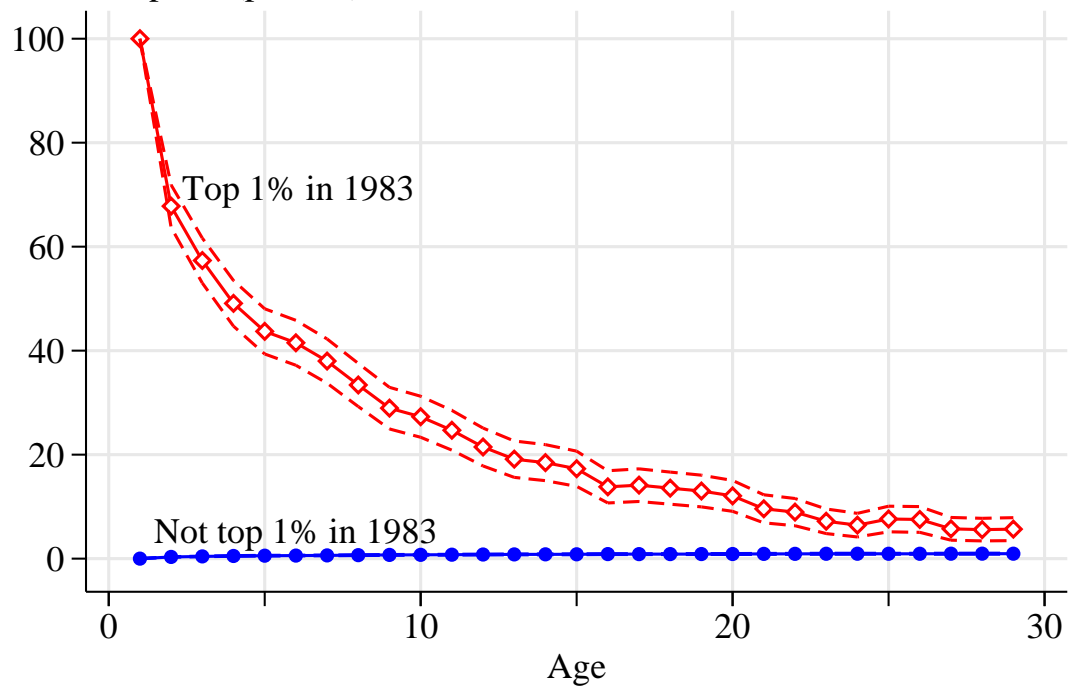

B. Age 18 in 1983

Share in top $1 \%$ (percent)

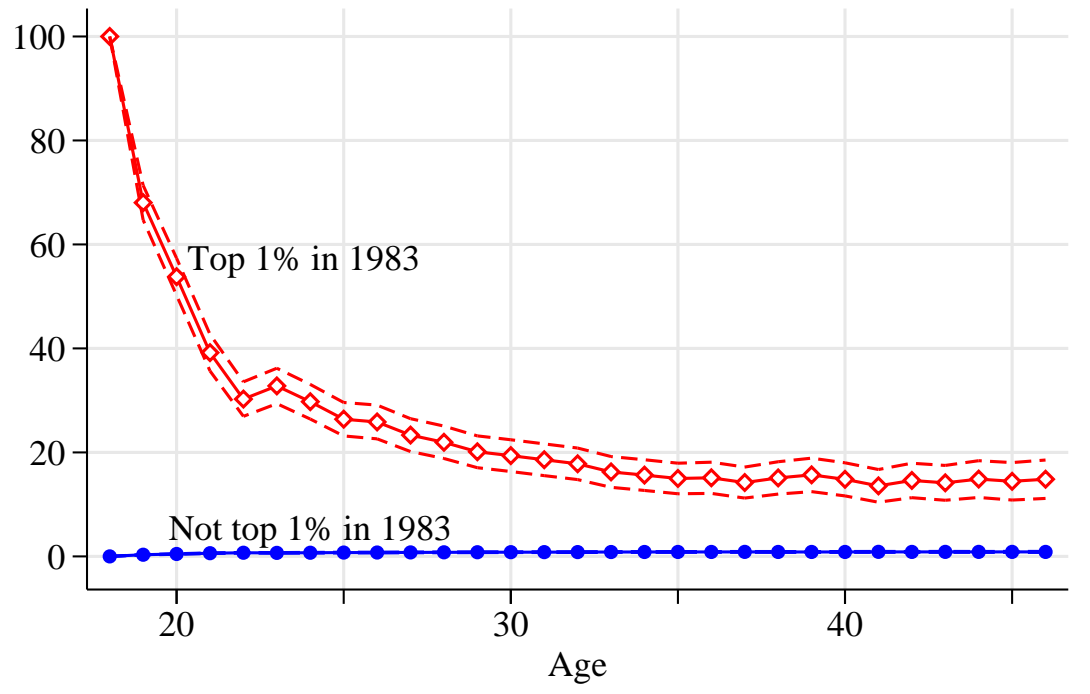

Figure E2: Survival rates of top wealth groups, 1983-2011

Notes: The graphs are based on the PD sample described in Table A2, supplemented with the 1982 birth cohort (panel A). The figures are constructed by first computing the within-cohort specific position/rank of the individuals at each age/year and then following the position of individuals who begin in the top 1\% wealth group by estimating for each age/year the share of individuals in this group who stay in the top 1\% wealth group (among those individuals originally present in 1983). In panel A, we look at the cohort of individuals who are one year old in 1983, and in panel B, we look at individuals who are eighteen years old in 1983 . The dashed lines represent $95 \%$ confidence bounds using robust standard errors. 


\section{F Potential bequests and the role of childhood wealth in predict- ing future wealth}

Table F1: Rank-rank regressions with dependent variable child wealth rank at age 45.

\begin{tabular}{lcccccc}
\hline \hline & $(1)$ & $(2)$ & $(3)$ & $(4)$ & $(5)$ & $(6)$ \\
\hline Child wealth rank (age 18) & 0.245 & 0.203 & 0.207 & 0.174 & 0.089 & 0.081 \\
& $(0.014)$ & $(0.014)$ & $(0.014)$ & $(0.014)$ & $(0.013)$ & $(0.013)$ \\
Parental wealth rank (when child was 18) & 0.169 & 0.079 & 0.145 & 0.071 & 0.067 & 0.041 \\
& $(0.014)$ & $(0.015)$ & $(0.014)$ & $(0.015)$ & $(0.013)$ & $(0.014)$ \\
Potential bequests & & 0.209 & & 0.184 & & 0.091 \\
& & $(0.015)$ & & $(0.015)$ & & $(0.014)$ \\
Earnings controls & & & $\mathrm{X}$ & $\mathrm{X}$ & $\mathrm{X}$ & $\mathrm{X}$ \\
Education dummies & & & $\mathrm{X}$ & $\mathrm{X}$ & $\mathrm{X}$ & $\mathrm{X}$ \\
Portfolio variables (when child was 18) & & & & & $\mathrm{X}$ & $\mathrm{X}$ \\
Child portfolio variables (when child is 45) & & & & & $\mathrm{X}$ & $\mathrm{X}$ \\
Constant & 29.299 & 25.461 & 23.964 & 21.524 & 46.338 & 44.412 \\
& $(0.839)$ & $(0.849)$ & $(1.693)$ & $(1.673)$ & $(1.764)$ & $(1.775)$ \\
\hline Observations & 5,469 & 5,469 & 5,469 & 5,469 & 5,469 & 5,469 \\
R-sq. & 0.115 & 0.146 & 0.147 & 0.170 & 0.395 & 0.400 \\
Adj. R-sq. & 0.115 & 0.146 & 0.143 & 0.166 & 0.390 & 0.395 \\
\hline \hline
\end{tabular}

Notes: Regressions in this table are based on the group of children in the 1965 age cohort who lose their last living parent-i.e., the same sample as in Table 4. Potential bequests are calculated as wealth of that parent the year prior to dying, divided by the number of children of that parent in the year of death. Potential bequests are ranked among potential bequests in the same year of death. In order that rankings make sense, we only use a year of death if there are at least 100 observed deaths. Thus, we use years from 1997-2011, where children are aged 32-46. Results are not sensitive to the choice of years. All other variables are defined exactly as in Table 3, and earnings controls correspond to including the same earnings controls as in columns 2, 3, or 6 in Table 3 . Robust standard errors in parentheses. 